\title{
LA CONFIGURACIÓN DE UNA HACIENDA \\ DE CARÁCTER FISCAL. EL CASO DE \\ SANTA CRUZ DE TENERIFE, 1850-1880
}

\author{
María del Pino Ojeda Cabrera \\ Universidad de La Laguna
}

\section{RESUMEN}

La pedanía de Santa Cruz de Tenerife accedió a la categoría de villa exenta en 1803, para luego adquirir el rango de capital provincial por el sistema político-administrativo propuesto por el régimen liberal. Por ello, el municipio debió constituir su hacienda de manera ex novo, aunque no consiguió disponer de los recursos económicos necesarios. Desde 1850, se creó una hacienda de carácter fiscal que hizo factible comenzar a dotar de bienes esenciales a la nueva urbe. Ello se vio acompañado de una mejora de sus actividades económicas, principalmente del comercio, el puerto e industrias asociadas. En el presente trabajo estudiaremos las transformaciones socioeconómicas que se produjeron a mediados del siglo xIx, para luego adentrarnos en el análisis de la nueva configuración de la hacienda municipal.

Palabras clave: historia económica, hacienda municipal, Santa Cruz de Tenerife.

\section{THE CONFIGURATION OF A FISCAL-TYPE MUNICIPAL TREASURY. THE CASE OF SANTA CRUZ DE TENERIFE, 1850-1880}

\section{Abstract}

The district of Santa Cruz de Tenerife acceded to the category of villa exenta in 1803, to then acquire the rank of provincial capital by the political-administrative system proposed by the liberal regime. For this reason, the municipality had to establish its treasury ex novo, although it did not manage to have the necessary economic resources. From 1850, it had a fiscal-type municipal treasury for the provision of essential services required by the new city. This was accompanied by an improvement in their economic activities, mainly in the commerce, the port and its associated industries. In the present work we will study the socioeconomic transformations that took place in the middle of the XIX century, to later get into the analysis of the new configuration of the municipal treasury.

Keywords: economic history, municipal treasury, Santa Cruz de Tenerife. 


\section{INTRODUCCIÓN}

La pedanía de Santa Cruz de Tenerife accedió a la categoría de villa exenta en 1803, para luego, durante la primera mitad de esta centuria, ver confirmado su rango de capital de la provincia de Canarias una vez instaurado el sistema políticoadministrativo propuesto por el régimen liberal. Pero la nueva villa exenta careció de la herencia que define la hacienda municipal de este período, de naturaleza esencialmente patrimonial. Por ello, el nuevo municipio debió constituir su hacienda de manera ex novo, aunque no consiguió disponer del caudal preciso para atender las exigencias propias de una urbe que pretendía ostentar la capitalidad de la región.

A partir de 1846 y, sobre todo, de 1850, esta historia financiera de nuestra entidad local, de continuados fracasos y parciales éxitos, alteró su curso. En efecto, entre la última fecha y 1880 , el municipio contó con una hacienda que respondió a las demandas de bienes esenciales de su vecindario; además, las actividades económicas mejoraron al incrementarse las que habían constituido su principal ocupación, es decir, el comercio, el puerto y sus industrias asociadas, e incorporarse ahora un contingente dedicado a las profesiones liberales y a los diversos ramos de la administración pública.

En base a lo dicho, las actividades productivas y profesionales del vecindario santacrucero sugieren que a mediados del siglo xix existía un tejido social que mostraba una mayor preocupación por mejorar los servicios esenciales mediante la construcción de nuevos establecimientos públicos, que era preciso atender con cargo a los ingresos municipales. En resumen, se trataba del verdadero desarrollo inicial de los indicadores de bienestar relativo que permiten sostener que fue durante esta etapa cuando el municipio comenzó a cimentar las bases de una futura urbe de corte moderno.

El presente trabajo tratará de aclarar, por un lado, las principales razones de este cambio económico y social y, por otro, la respuesta que dio el municipio a la creciente demanda de aquellos bienes preferentes que se consideraban esenciales a mediados del siglo xIx. Una respuesta que exigió la formación y posterior desarrollo de una hacienda municipal distinta a la del pasado, y, asociada a ella, el desarrollo de una economía que hiciera llegar a dicha hacienda los recursos financieros precisos para poder atender en lo posible aquella progresiva demanda.

El municipio, escasamente, contaba un patrimonio histórico cifrado en las propiedades del Hospital de Nuestra Señora de los Desamparados y otros cortos bienes en el capítulo de beneficencia que, como en la mayoría de los municipios, perdió durante la desamortización civil, al tiempo que desaparecieron las pocas rentas procedentes de los arbitrios sobre la circulación de mercancías al suprimir estos arbitrios las disposiciones liberales en materia del mercado interior ${ }^{1}$.

${ }^{1}$ Los arbitrios sobre la exportación e importación se suprimieron durante el período anterior y el haber del peso en 1855 . 
Ahora, la nueva hacienda debía nutrirse casi por entero de ingresos procedentes de impuestos sobre la actividad económica. La reforma de la hacienda estatal de Mon-Santillán (1845) sentó las bases de una nueva hacienda de carácter fiscal, así como su vía de financiación mediante recargos sobre las contribuciones estatales, especialmente en los impuestos sobre los principales bienes de consumo. La nueva hacienda únicamente era factible si contaba con una saneada economía productiva o, mejor dicho: como aquellos impuestos recaían sobre los principales artículos de consumo y, por tanto, afectaban a la población que vivía del pan de la plaza, los ingresos de la nueva hacienda municipal de carácter fiscal dependían de la existencia de un amplio colectivo de consumidores con rentas del trabajo en la cuantía precisa para poder soportar la creciente imposición fiscal indirecta.

Por suerte, la fuerza motriz de la economía agroexportadora conoció entre 1850 y 1880 una nueva y singular expansión productiva, ligada a Inglaterra. Una expansión que procuró un fuerte crecimiento de la población y de las rentas de la tierra y del trabajo, al tiempo que aumentó el nivel de empleo en las áreas urbanas para atender la creciente demanda de una población rural con una mayor dependencia del mercado como consecuencia del proceso de proletarización campesina generado durante el período anterior ${ }^{2}$, de crisis y de cambios en la titularidad de la tierra, agrandados ahora con la desamortización civil.

Por su parte, la economía de servicios marítimos de los puertos insulares desempeñó igual papel al recuperar y ampliar su tradicional vinculación al tráfico internacional. Todo ello fue también posible por la renovación del viejo pacto institucional con el Estado. Suprimido el proteccionismo, el Archipiélago recuperaba su ancestral vocación librecambista. Por consiguiente, comencemos nuestro análisis por este cambio de coyuntura, para luego detenernos en el estudio de la nueva hacienda local santacrucera.

\section{MARCO INSTITUCIONAL Y CRECIMIENTO ECONÓMICO. LA VÍA ISLEÑA AL CAPITALISMO: LAS FRANQUICIAS}

Las causas que explican la nueva coyuntura de la economía insular tuvieron que ver con un cambio de singular calado a nivel institucional ${ }^{3}$. El nuevo Estado debía tener muy presentes las claves de una historia económica isleńa vinculada al escena-

2 Ojeda Cabrera, María del Pino (2018): «La compleja puesta en marcha de la hacienda municipal de Santa Cruz de Tenerife, 1820-1850». Vegueta. Anuario de la Facultad de Geografía e Historia, 18, pp. 367-402.

${ }^{3}$ Bernal, Antonio Miguel y Macías, Antonio Manuel (2007): «Canarias, 1400-1936. El Modelo de Crecimiento en Perspectiva Histórica», en Economía e Insularidad (siglos XIV-XX), La Laguna, pp. 11-52. 
rio internacional. Se trataría de buscar fórmulas de consenso que hicieran factible una política económica y fiscal acorde con los intereses de los isleños y de su Estado ${ }^{4}$.

En este sentido, se discutieron dos opciones ${ }^{5}$. La primera sería de total ruptura con el proteccionismo y, por tanto, con el mercado de la España peninsular. Se basaría, pues, en el establecimiento de un puerto franco, tal y como habían solicitado los agentes insulares a la Corona en 1827 mediante Alonso de Nava Grimón $^{6}$, marqués de Villanueva del Prado y defensor del absolutismo, de modo que la labor que se debería realizar ahora sería la de darle a dicha ruptura negociada con el Estado su correspondiente contenido jurídico-administrativo, fiscal y económico.

La segunda opción debía centrarse en una reforma arancelaria que redujera su negativa incidencia sobre las relaciones reales de intercambio con el exterior y en la reducción de los derechos sobre la entrada de la marina extranjera en los puertos insulares para poder maximizar los beneficios de su economía de servicios marítimos.

No obstante, todo ello generó posturas divididas. Los que apostaban por la opción moderada presentaron un frente cohesionado contra el puertofranquismo, aunque carecían del peso político local necesario para hacer triunfar su postura. En realidad, constituían un grupo de comerciantes, minoritario, de origen peninsular, asentados en el núcleo urbano-portuario de Santa Cruz que habían llegado con el proteccionismo y, por ello, se declararon en contra de las franquicias. Al hacerlo, manifestaban sus intereses que "arruinarían nuestra marina, comercio e industria, de Cataluña y Baleares en particular»?.

De otra parte, la clase mercantil y la clase terrateniente agroexportadora opinaron que aquella opción moderada ya se había ensayado sin éxito alguno con el arancel canario de $1831^{8}$. Las franquicias obviarían, a su juicio, este problema, sobre todo cuando Inglaterra, el histórico socio del comercio exterior isleño, que iniciaba su desarme arancelario (1844), requería los servicios del enclave insular para atender su creciente comercio ultramarino ${ }^{9}$ y comenzaba sus compras de cochinilla; un producto agroexportador cuyo crecimiento fuera del proteccionismo, es decir, compitiendo con la grana de Centroamérica, no era posible sin reducir los costes de transacción que limitaban las ventas a su principal comprador industrial.

de Tenerife.

${ }^{4}$ Guimerá Peraza, Marcos (1989): Los puertos francos en el siglo XIX. Textos, Santa Cruz

5 Bernal, Antonio Miguel (1981): «En torno al hecho económico diferencial canario». En Canarias ante el Cambio, Santa Cruz de Tenerife, pp. 25-38; Macías, Antonio Manuel (1987): "Canarias, 1800-1870. Fiscalidad y Revolución burguesa». Revista de Hacienda Pública, 108-109, pp. 327-342; Bernal y Macías (2007): op. cit., p. 39.

${ }^{6}$ Nava, Alonso (1988): Escritos Económicos. Canarias: Economía e Ilustración. Santa Cruz de Tenerife, pp. 295-307.

7 Macías (1987): op. cit., p. 386.

8 Bourgón, Luis Pablo (1987): Los Puertos Francos y el Régimen Especial de Canarias. Madrid, 1982, p. 48; MaCías: op. cit., pp. 381-383.

9 Minchinton, Walter (1984): «The Canaries as port of calls». VI Coloquio de Historia Canario-Americana, 1, pp. 273-300. 
Lo dicho sugiere que la elite agromercantil defensora de la opción librecambista hacía una lectura de la historia económica insular en los términos que mejor convenían a sus intereses de clase. De ahí que sostuvieran con ahínco que una vez liberada la economía isleńa de cualquier obstáculo que impidiera su acceso al mercado internacional, tal circunstancia animaría el flujo comercial en los puertos insulares y sus comisiones beneficiarían a la clase mercantil. Finalmente, consideraban que la eliminación de los aranceles elevaría la competitividad de la oferta agroexportadora y mejoraría su relación real de intercambio, de modo que las franquicias triunfaron.

Ahora bien, su triunfo no llegó hasta la década de 1840, cuando se aprobó la gran reforma de la hacienda española. En este sentido, la estrategia de puerto franco tropezaba con una Hacienda que defendía a toda ultranza sus rentas de aduanas y el monopolio del tabaco, pues representaban por término medio el $65 \%$ de los ingresos fiscales que percibía en Canarias. En consecuencia, la liberalización del tráfico exterior mediante la rebaja o supresión de los derechos de aduanas y de otros renglones gravosos al comercio y a la circulación interior, así como la eliminación del monopolio del tabaco, no podían significar una disminución de los ingresos fiscales. Era preciso arbitrar una fórmula de compromiso entre los intereses del Tesoro y la justificada estrategia librecambista.

Esta fórmula se concretó en el Real Decreto de 11 de julio de 1852. Declaró puertos francos a todos los puertos insulares (El Hierro accedió a la franquicia en 1870) y fijó el cupo que se abonaría a la Hacienda por la supresión de las aduanas y el estanco del tabaco. Este cupo ascendía a 1215811 reales y sería pagado por la Diputación y la Junta de Comercio, responsables ante el Tesoro, mediante los siguientes derechos: los arbitrios de puertos francos, consistentes en un derecho sobre el tabaco y el uno por mil sobre la entrada de mercancías; lo recaudado por la importación de granos y harinas extranjeras según el arancel de 1831; y un recargo del $2 \%$ sobre la contribución territorial y otro del $50 \%$ sobre la comercial ${ }^{10}$.

\subsection{LAS NUEVAS RESPUESTAS DE LA ECONOMÍA INSULAR}

La noticia del otorgamiento de las franquicias se celebró en las principales urbes canarias ${ }^{11}$. Así, cabe agregar que la vía isleña al capitalismo encontró el marco institucional adecuado. A partir de ahora se produjo un proceso de cambio social y productivo que afectó con desigual fortuna a todo el escenario social y político regional ${ }^{12}$.

${ }^{10}$ Bourgón (1982): op. cit., pp. 35-101.

${ }^{11}$ Macías, Antonio Manuel (2011): «Canarias, 1800-2000: La singularidad de la historia económica isleña». Historia Contemporánea, 42, pp. 225-259.

12 Macías, Antonio Manuel: «Economía y política en el librecambio isleño», en Macías Hernández, A.M. (2003): Revisiones y Provocaciones. Diez artículos de Historia Económica de Canarias, Santa Cruz de Tenerife, pp. 397-413. 
La primera etapa de este proceso transcurrió entre 1850 y 1880, cuando la economía de producción agroexportadora y la economía de servicios maritimos iniciaron su despegue contemporáneo, arropadas ambas por una política económica y fiscal que, de nuevo, potenciaba su desarrollo.

Desde 1820, la elite rural emprendedora que había ensayado nuevas variedades de papas con destino a la exportación, especialmente al Caribe, importando al efecto las primeras variedades foráneas, luego, en el último tercio del siglo XIX, serían las protagonistas de los envíos a los mercados europeos ${ }^{13}$.

La franquicia suprimió el monopolio del tabaco, por cuanto gran parte de su renta se destinaba a combatir sin éxito el contrabando y porque el Estado y las elites insulares defensoras de la franquicia convinieron en que se trataba de una agroindustria que podía adquirir un gran desarrollo en el Archipiélago ${ }^{14}$. La causa radica en que aquel contrabando obedecía no sólo a la importación clandestina de tabacos de Cuba, sino también a las plantaciones urbanas clandestinas para el autoconsumo.

El esfuerzo innovador de una minoría emprendedora sentó las bases de la opción agroexportadora diseñada desde 1820. Aludimos al nopal y a su parásito, la grana o cochinilla, un minúsculo insecto $\left(\right.$ Coccus cacti) ${ }^{15}$ que procuraba un ácido carmínico empleado como tinte por los indígenas centroamericanos y por la industria textil europea desde finales del siglo Xvi a través de sus compras en el mercado sevillano. La pérdida de las colonias sudamericanas obligó a la industria hispana a solicitar el apoyo del Estado para potenciar la aclimatación y el desarrollo del nopal y su grana en el sur de la Península y particularmente en Canarias.

La nueva oferta agroexportadora inició su andadura en la década de 1830, vinculada en principio a la demanda de la industria nacional. Las 1319 libras de cochinilla exportadas en 1833 se multiplicaron por cinco tres ańos más tarde y por 16 en 1841, al alcanzar la cifra de 100566 libras. Y como Tenerife fue el epicentro del inicio del cultivo, durante sus primeros años fue la principal isla productora, con el 75,2 por ciento del total exportado entre 1833-42, seguida de Gran Canaria y Lanzarote ( $c f$. tabla 1$)$.

La cochinilla fue el primer renglón exportador vinculado al mercado europeo, fundamentalmente, desde el establecimiento de los puertos francos. Ahora, se redujo el precio de los inputs solicitados por los productores de grana, así como sus costes de transacción como consecuencia de la libre entrada de toda la navegación

${ }_{13}$ Macías, Antonio Manuel: «La papa en la economía canaria, 1548-1850. Historia de un éxito campesino", en Jaizme-Vega, M.C., Cid Ballarín, M.C. y Bello Pérez, A. (eds.) (2009): La papa, un cultivo y una cultura con valores agroecológicos, Santa Cruz de Tenerife, pp. 7-29.

${ }^{14}$ LuxÁn, Santiago: «El Real Decreto de Puertos Francos y el desestanco del tabaco (18271852)", en S. LuxÁN (coord.) (2004): Los puertos francos de Canarias. Ciento cincuenta años de historia. Las Palmas de Gran Canaria, pp. 141-207.

15 Morales Lezcano, Víctor (1972): «Producción, precios y distribución de la cochinilla», Revista Canaria de Economía, 4, pp. 192-215; Macías, Antonio Manuel (1990): «El papel de la agricultura en el desarrollo regional en la Europa mediterránea, 1750-1980. Canarias, 1830-1890». Areas: Revista Internacional de ciencias sociales, 12, 239-252. 
atlántica a los puertos isleños, lo cual mejoró su competencia con la grana de la América Central, al verse dañada por una plaga posteriormente. Las exportaciones pasaron de medio millón a un millón de kilos en 1860-1861 y a dos millones en 1868, alcanzando su techo de dos millones y medio en la década de 1870 .

\begin{tabular}{|c|c|c|c|c|c|c|}
\hline \multicolumn{7}{|c|}{$\begin{array}{c}\text { TABLA 1. DISTRIBUCIÓN DE LAS EXPORTACIONES DE GRANA } \\
\text { ENTRE LAS ISLAS PRODUCTORAS (MEDIAS ANUALES) }\end{array}$} \\
\hline \multirow{2}{*}{ Islas } & \multicolumn{2}{|c|}{$1833-1842$} & \multicolumn{2}{|c|}{$1853-1860$} & \multicolumn{2}{|c|}{$1877-1879$} \\
\hline & Libras & $(\%)$ & Libras & $(\%)$ & Libras & $(\%)$ \\
\hline Tenerife & 24614 & 75,2 & 848531 & 79,4 & 1954444 & 37,3 \\
\hline Gran Canaria & 5420 & 16,6 & 146086 & 13,7 & 3026097 & 57,8 \\
\hline Lanzarote & 2005 & 6,1 & 52957 & 5,0 & 141313 & 2,7 \\
\hline Fuerteventura & 688 & 2,1 & & & & \\
\hline La Palma & & & 20683 & 1,9 & 117841 & 2,2 \\
\hline Totales & 32727 & 100 & 1068257 & 100 & 5239695 & 100 \\
\hline
\end{tabular}

Las franquicias abrieron los puertos a la navegación atlántica de todas las potencias marítimas sin límites de bandera y obstáculos arancelarios; retornaba, pues, aquel marco institucional del siglo Xvi que había propiciado el desarrollo de una economía de servicios maritimos. De ahí que esta economía recuperase su dinamismo e iniciara una senda de sostenido crecimiento cuyo ritmo corrió paralelo al del tráfico internacional que frecuentaba los puertos insulares para suministrarse de toda clase de bienes y, sobre todo, de aguada y carbón mineral importado a medida que avanzaba la modernización del transporte marítimo ${ }^{16}$.

Asimismo, las franquicias posibilitaron la modernización del tejido industrial isleño al poner a disposición de las actividades secundarias materias primas y energía importadas a precios internacionales, ampliando la dimensión de su mercado a medida que crecía la demanda de los buques en tránsito y se afianzaba la del nuevo escenario colonial africano. Y agreguemos, también, el cambio ocurrido en las industrias ligadas a la actividad portuaria vinculada a la metalurgia, que debía atender ahora las precisas reparaciones navales de los buques con armazón de hierro y movidos por la fuerza del vapor.

La expansión de las economías de servicios y agroexportadora procuró el crecimiento de los intercambios interiores y exteriores, al mejorar la capacidad de los insulares para adquirir bienes de equipo y manufacturas de procedencia foránea. Por consiguiente, el aumento de la cuota de mercado correspondiente a los bienes foráneos acentuó a medio y largo plazo el proceso de proletarización campesina ${ }^{17}$.

16 Pérez Hernández, Concepción (2016): Energía y desarrollo económico en Canarias. Un análisis histórico (tesis doctoral inédita). Universidad de La Laguna.

17 Ojeda Quintana, José Juan (1977): La desamortización en Canarias (1836 y 1855). Las Palmas de Gran Canaria. 
Un nuevo marco que indujo a que muchas unidades familiares emplearan dosis crecientes de su fuerza de trabajo en las nuevas opciones productivas.

El cultivo del nopal y el tratamiento de su insecto exigieron la contratación de una numerosa fuerza de trabajo masculina y femenina, favoreciendo que los salarios de la primera se duplicaran entre 1850 y 1870. Asimismo, la expansión de la economía de servicios potenció el nivel de empleo, especialmente en el caso de la construcción y del transporte, donde se recurrió a la contratación de mano de obra rural; de ahí que los salarios de los peones y albañiles también se multiplicaron por dos en dicho período ${ }^{18}$.

En resumen, concluimos que durante el período $1850-1880$ se produjo un importante crecimiento de las rentas del trabajo, de la tierra y del capital, de modo que el tejido social y económico isleño era favorable a la construcción de una nueva hacienda local, de carácter fiscal, y fundamentada en la imposición indirecta.

\section{DESPEGUE URBANO}

Santa Cruz de Tenerife durante este período cimentó las bases de su posterior crecimiento urbano moderno. Entre 1845 y 1857, la tasa anual acumulativa de la población fue del 3,03 por ciento, algo superior a la experimentada por la población de Las Palmas, para caer luego al 1,21 por ciento entre 1857 y 1877 (cf. tabla 2), al tiempo que la participación porcentual de la población santacrucera en el total insular no hizo sino crecer durante este período (del 10,7 al 15,1 por ciento). En resumen, la población de hecho de Santa Cruz de Tenerife se multiplicó por dos entre 1845 y 1877.

TABLA 2. POBLACIÓN DE LOS PRINCIPALES NÚCLEOS URBANO-PORTUARIOS

\begin{tabular}{|c|c|c|c|c|c|c|c|c|}
\hline \multirow{2}{*}{ NúCleos } & \multicolumn{2}{|c|}{1845} & \multicolumn{3}{|c|}{1857} & \multicolumn{3}{|c|}{1877} \\
\hline & НАв. & $(\%)$ & НАв. & $(\%)$ & TASA & НАв. & $(\%)$ & TASA \\
\hline Santa Cruz de Tenerife & 8728 & 10,7 & 12486 & 13,5 & 3,0 & 15885 & 15,1 & 1,2 \\
\hline Puerto de la Cruz & 3863 & 4,7 & 3514 & 3,8 & $-0,8$ & 4213 & 4,0 & 0,9 \\
\hline Las Palmas de Gran Canaria & 11442 & 16,8 & 16329 & 24,0 & 3,0 & 20914 & 23,2 & 1,3 \\
\hline Santa Cruz de La Palma & 5147 & 15,6 & 5216 & 16,6 & 0,1 & 6619 & 17,0 & 1,2 \\
\hline
\end{tabular}

Nota: (\%) sobre el total de la población insular.

Fuente: para 1845, véase Macías, Antonio Manuel: La población de Canarias (c. 1400-1850). Manuscrito. Para el resto de los ańos, los datos de los censos de 1857 y de 1877.

La mortalidad no manifestó grandes cambios a pesar de la epidemia de fiebre amarilla. En gran medida el crecimiento se debió a una corriente inmigratoria del exterior y del interior de la isla, por la atracción de las nuevas opciones productivas que se desarrollaban en el municipio santacrucero. Es más, el principal aporte inmigratorio se produjo en los años 1845-1857, aunque ello no derivó en un fenó-

18 Macías (1990): op. cit., p. 245. 
meno de presión inmobiliaria ${ }^{19}$. A partir de 1850 , su incremento se debió a la necesidad de dotar a la urbe de almacenes y tiendas vinculadas a la creciente actividad mercantil y portuaria, provocando el encarecimiento del suelo urbano.

Las actividades portuaria y mercantil constituían los dos principales renglones económicos de Santa Cruz, de modo que la principal fuerza motriz de esta inmigración estaría en la expansión de estas actividades, favorecidas ahora por las franquicias. Pero el examen de la población activa santacrucera, tal y como aparece reflejada en el censo de 1860 ( $c f$. tabla 3), altera la herencia del anterior modelo, al tiempo que otorga una mayor complejidad a la economía del municipio.

\begin{tabular}{|c|c|c|c|c|c|}
\hline \multirow{2}{*}{$\begin{array}{l}\text { SeCTORES DE } \\
\text { ACTIVIDAD }\end{array}$} & \multirow{2}{*}{ Activos } & \multirow{2}{*}{$(\%)$} & Terciario & Activos & $(\%)$ \\
\hline & & & Comerciantes & 400 & 29,5 \\
\hline Primario & 1843 & 45,2 & Sirvientes & 324 & 23,9 \\
\hline Secundario & 877 & 21,5 & Marinos & 227 & 16,7 \\
\hline Terciario & 1356 & 33,3 & Profesionales & 405 & 29,9 \\
\hline Totales & 4076 & 100 & Totales & 1356 & 100 \\
\hline
\end{tabular}

Nota: en el primario no se ha incluido el grupo de propietarios.

Fuente: Olive: op. cit., 1865, p. 1003. Elaboración propia.

Asimismo, en esta década surgió en las urbes canarias un asociacionismo obrero de inspiración católica y gremial ${ }^{20}$. En cuanto a su estructura, observamos que la actividad industrial daba trabajo al 21,5 por ciento del total de activos y los servicios al 33,3 por ciento, pero destaca ahora en este bloque el grupo dedicado a la administración y a las profesiones liberales $(29,9 \%)$, que ocupa el mismo rango que el de los comerciantes y sus empleados (29,5\%). En síntesis, de ello se deriva la presión inmobiliaria surgida en Santa Cruz, que, por entonces, se dio en la Europa de la industrialización y que tuvo una temprana presencia en las principales ciudades canarias, en consonancia con su vinculación internacional ${ }^{21}$. Un marco, este, que

19 En 1800, el casco urbano de Santa Cruz contaba con 1700 casas útiles y 46 arruinadas; en 1845, con 1900. Véase Hernández Rodríguez, Germán (ed.) (1983): Estadística de las Islas Canarias. 1793-1806. De Francisco Escolar y Serrano. Las Palmas de Gran Canaria, p. 147; Madoz, Pascual (1986): Diccionario Geográfico-Estadístico-Histórico de España y sus Posesiones en Ultramar, 1845-1850, Canarias. Valladolid, p. 198.

${ }^{20}$ Brito, Oswaldo (1980): Historia del movimiento obrero canario. Madrid, pp. 57-60.

${ }^{21}$ Carnero, Fernando y Nuez, Juan Sebastián (2003): «Aspectos económicos y financieros de las empresas constructoras de casas baratas en Canarias, c. 1850-1936». Anuario de Estudios Atlánticos, (49), pp. 475-507; Darias Príncipe, Alberto y Purriños, Teresa (1987): «Las sociedades constructoras en Canarias». VI Coloquio de Historia Canario-Americana, 2, pp. 629- 672; SÁNCHEZ DE ENCISO, Alberto (1988): «Las sociedades constructoras canarias entre 1866 y 1878». Anuario de Estudios Atlánticos, 34, pp. 507-563; Sosa, Javier y GonzÁlez Rodríguez, Candelaria (1994): "Sociedades constructoras en Las Palmas durante el siglo XIX». Coloquio de Historia Canario-Americana, 10, pp. 579-601. 
dio paso a la creación de la Sociedad Constructora de Edificios Urbanos de Santa Cruz de Tenerife, representada por diferentes firmas.

No obstante, un sector de la población del municipio siguió vinculado al sector primario ( $45 \%$ de activos) (cf. tabla 3), lo que generó un elevado nivel de contratación de fuerza de trabajo asalariada. Comencemos, pues, por aclarar este punto, por cuanto debe tenerse en cuenta a la hora no sólo de discutir los ingresos de la hacienda municipal, sino porque aquella nueva economía agraria en el espacio santacrucero afectó negativamente al patrimonio de aquella hacienda y le privó de un ingreso patrimonial, el hídrico, cuya carencia debió luego atender el municipio por el lado del gasto.

\subsection{LA PRIMERA OPCIÓN AGROEXPORTADORA}

Como ya se ha indicado, Santa Cruz carecía de los recursos hídricos superficiales que exigía el desarrollo de la oferta agroexportadora. A las elites santacruceras no se les escapó la importancia que suponía contar con esta oferta en el municipio con el fin de potenciar su función urbano-portuaria.

Era preciso, pues, aumentar los recursos hídricos disponibles, y como las únicas aguas superficiales que nacían en el municipio se localizaban en su patrimonio comunal, es decir, en la cuenca hidrográfica que conformaba el Monte Aguirre, y sus aguas tenían como prioritario objeto cubrir el abasto del vecindario, la expansión de la nueva oferta agroexportadora nació asociada a la demanda hídrica del vecindario santacrucero.

Por consiguiente, cabe afirmar que el gran proyecto de canalización de las aguas de Santa Cruz, iniciado en 1828 y finalizado seis años más tarde, supuso poner a disposición del vecindario un caudal promedio de algo más de $80000 \mathrm{~m}^{3}$ anuales de agua que tuvo por objeto ampliar el regadío (35\%), y el sobrante fue aprovechado para la expansión de la grana ${ }^{22}$, aunque fue insuficiente. Entonces comenzó el proceso desamortizador del subsuelo hídrico mediante concesiones municipales de obras de alumbramiento en el patrimonio municipal ${ }^{23}$. Pero, si bien sus promotores debían garantizar el abasto público, destinando los sobrantes al regadío, parte de los cauces fueron desviados de modo que en la década de 1850 el municipio comenzó a sufrir la disminución de sus caudales, con la consiguiente merma de dicho abasto ${ }^{24}$.

22 Así, en 1857 más de la mitad del agua vendida por la municipalidad tenía como destino el regadío. Véase Cola, Luis (2009): Sed. La Odisea del agua en Santa Cruz de Tenerife. Santa Cruz de Tenerife, p. 101.

${ }^{23}$ Macías, Antonio Manuel y Ojeda Cabrera, María del Pino (1989): «Acerca de la Revolución Burguesa y su Reforma Agraria. La desamortización del agua». Anuario de Estudios Atlánticos, 35, pp. 217-260; Macías, Antonio Manuel (2000): "De "Jardín de las Hespérides" a "Islas sedientas”. Por una historia del agua de las Canarias, c. 1400-1990", en Barciela López, C. y Melgarejo Moreno, J.: El agua en la Historia de España. Alicante, pp. 171-274.

${ }^{24}$ Cola (2009): op. cit., pp. 102-114. 
El esfuerzo histórico por la defensa de la causa pública en materia hídrica hizo necesario ahora invertir considerables sumas en subsanarlo, recurriendo cada vez más a la compra de los mismos caudales que antes fueron propiedad municipal.

\subsection{El DESARRollo DE LA ACTIVIDAD PORTUARIA}

El nopal y su grana y la ampliación del área irrigada, asociada a la inversión municipal en el abastecimiento urbano, dieron el mayor valor agrario a los áridos secanos de Santa Cruz. Además, la cochinilla se extendió por los municipios colindantes y llegó hasta Guía de Isora, exigiendo sus productores una salida a este nuevo renglón agroexportador y un mejor abastecimiento de los inputs que demandaban sus economías familiares, teniendo como único enclave portuario el de Santa Cruz de Tenerife.

\begin{tabular}{lrrrr}
\hline \multicolumn{4}{c}{ TABLA 4. VALOR ADUANERO DE LAS IMPORTACIONES. AÑOS INDICADOS } \\
\cline { 2 - 5 } Puertos & \multicolumn{3}{c}{1852} & \multicolumn{3}{c}{1861} \\
& \multicolumn{1}{c}{ (PTAs.) } & \multicolumn{1}{c}{$(\%)$} & $($ PTAs.) & \multicolumn{1}{c}{$(\%)$} \\
\hline Santa Cruz de Tenerife & 572997 & 49,6 & 3847831 & 48,3 \\
\hline Santa Cruz de La Palma & 15543 & 1,3 & 486372 & 6,1 \\
\hline Las Palmas de Gran Canaria & 501393 & 43,4 & 2747097 & 34,5 \\
\hline Lanzarote & 40098 & 3,5 & 395405 & 5,0 \\
\hline Fuerteventura & 25622 & 2,2 & 496976 & 6,2 \\
\hline Totales & 155652 & 100 & 7973681 & 100 \\
\hline
\end{tabular}

Fuente: estadísticas de comercio exterior de la Dirección General de Aduanas. Elaboración propia.

El núcleo urbano-portuario santacrucero recuperó su tradicional papel geoestratégico en las comunicaciones atlánticas, también gracias a las franquicias, y su enclave portuario recibió la categoría de puerto de interés general en 1852. Se inició entonces la construcción, con cargo a los presupuestos del Estado, de la infraestructura portuaria que permitiera las operaciones de los modernos buques de vapor ${ }^{25}$.

Pero en su expansión se observa una pérdida de su hegemonía en la actividad portuaria y comercial del Archipiélago, cuando comenzó a competir con el núcleo urbano-portuario de Las Palmas ( $c f$. tabla 4). Quedaba amenazado, pues, el futuro de una urbe cuyo desarrollo se fundamentaba en el papel portuario y comercial que otorgaba el disfrute de aquella hegemonía. Y de ello se deduce que tal amenaza no era propicia al desarrollo de una hacienda municipal en consonancia con el rango capitalino.

${ }^{25}$ Murcia, Emilio (1975): Santa Cruz de Tenerife, un puerto de escala en el Atlántico. Santa Cruz de Tenerife, pp. 25-28; Cioranescu, Alejandro (1998): Historia de Santa Cruz de Tenerife, 1803-1977. Santa Cruz de Tenerife, t. III, pp. 577-583. 


\section{LA NUEVA HACIENDA MUNICIPAL: LOS INGRESOS}

La hacienda patrimonial del Antiguo Régimen se había deteriorado por las propias exigencias financieras de la Hacienda regia, especialmente durante los años de la Guerra de la Independencia. Igual efecto tuvieron las ventas de los baldíos comunes a censo reservativo, propiciadas por el liberalismo; y si bien las rentas que abonaban los censualistas aliviaron la hacienda de algunos municipios ${ }^{26}$, lo perdieron luego cuando la desamortización civil autorizó la redención de los censos.

Un proceso en el que liberalismo, propiedad común y caciquismo se dieron la mano, en tanto que los defensores de aquella ideología eran a su vez los administradores de la causa pública. Alcanzó su punto álgido con la desamortización de Madoz (1855), cuando el Estado procuró la venta de todos los bienes de Propios en beneficio de su Hacienda, prometiendo a los municipios el pago del 80 por ciento de su valor mediante títulos intransferibles de deuda pública consolidada al 3 por ciento anual ${ }^{27}$. Sin embargo, los municipios no solamente perdieron el 20 por ciento del valor de sus bienes y el lucro cesante que les reportaban sus rentas, puesto que el 3 por ciento de deuda consolidada era inferior al importe de dichas rentas, sino que, además, perdieron también este rédito al no cumplir fielmente el Estado su compromiso de pago.

No obstante, este proceso dejó de lado a la hacienda del municipio de Santa Cruz al no contar con apenas patrimonio en bienes rústicos y urbanos ${ }^{28}$. Pero las licencias concedidas por el Consistorio a particulares y empresas para las obras de alumbramiento de aguas en su propiedad comunal muestran el alcance del proceso desamortizador, así como lo ocurrido en el caso del principal patrimonio municipal asignados expresamente al capítulo de beneficencia del presupuesto de gastos municipales: la enajenación de los bienes del patrimonio fundacional del Hospital de Nuestra Señora de los Desamparados.

Fundado a mediados del siglo XVIII, estaba constituido básicamente por bienes rústicos en las jurisdicciones de Santa Cruz y La Laguna, respectivamente, y dedicados a las sementeras y al pastizal y de reducido valor económico, de modo que los bienes principales eran las propiedades urbanas (casas y huertas) situadas en el casco urbano de Santa Cruz de Tenerife. Estos últimos bienes reportaban a la administración del Hospital en 1855 un ingreso bruto anual de 2637,75 pesetas ( $c f$.

${ }^{26}$ Se constata con los repartimientos de baldíos ordenados por la Real Audiencia en diversos pueblos. Véase Madoz (1986): op. cit., p. 229.

27 Comín, Francisco (1996): Historia de la Hacienda Pública. Vol. II: España (1808-1995). Barcelona, pp. 90-101.

${ }_{28}$ Así ocurrió en el caso de la hacienda municipal de San Cristóbal de La Laguna. Véase Macías, Antonio Manuel: «Aportación al Estudio de las Haciendas Locales: Los presupuestos del Ayuntamiento de La Laguna (1772-1851)». Revista de Historia Canaria, 37, (1983), pp.111-159. 
tabla 5), de las que debían descontarse sus tributos y otras pensiones, por valor de 184,84 pesetas $^{29}$, de modo que el ingreso neto en dicho año fue de 2452,91 pesetas.

\begin{tabular}{|c|c|c|c|c|}
\hline \multicolumn{5}{|c|}{$\begin{array}{l}\text { TABLA 5. RELACIÓN DE PROPIEDADES URBANAS DEL HOSPITAL } \\
\text { DE NTRA. SRA. DE LOS DESAMPARADOS }\end{array}$} \\
\hline Tipo & Municipio & Calle & Núm. & Renta \\
\hline Casa & Sta. Cruz & San Carlos & 22 & 180,0 \\
\hline Casa & Sta. Cruz & La Noria & 9 & 225,0 \\
\hline Casa & Sta. Cruz & La Noria & 41 & 225,0 \\
\hline Casa & Sta. Cruz & Candelaria & 6 & 360,0 \\
\hline Casa & Sta. Cruz & Norte & 9 & 157,5 \\
\hline Casa & Sta. Cruz & San Francisco & 24 & 90,0 \\
\hline Casa & Sta. Cruz & San Francisco & 25 & 90,0 \\
\hline Casa & Sta. Cruz & San Francisco & 26 & 112,5 \\
\hline Casa & Sta. Cruz & San Juan Bautista & 32 & 90,0 \\
\hline Casa & Sta. Cruz & San Juan Bautista & 34 & 45,0 \\
\hline Casa & Sta. Cruz & San Lorenzo & 19 & 50,5 \\
\hline Casa & Sta. Cruz & San Lorenzo & 20 & 50,5 \\
\hline Casa & Sta. Cruz & San Roque & 10 & 50,5 \\
\hline Casa & Sta. Cruz & San Felipe Neri & 19 & 112,5 \\
\hline Casa & Sta. Cruz & San Felipe Neri & 20 & 45,0 \\
\hline Casa & Sta. Cruz & Cruz Verde & 6 & 180,0 \\
\hline Casa & La Laguna & El Remojo & & 105,0 \\
\hline Huerta & Sta. Cruz & Ferrer & & 150,0 \\
\hline Huerta & Sta. Cruz & San Carlos & & 318,8 \\
\hline \multicolumn{4}{|l|}{ Total } & 2637,8 \\
\hline
\end{tabular}

Fuente: AMSCT. Presupuestos, caja 1.1174, exp. 4. Elaboración propia.

Veamos ahora su desamortización. Exceptuando la casa terrera situada en la calle Cruz Verde y la casa de la calle Candelaria, que se vendieron en 1858 y 1859 , respectivamente, el resto del patrimonio se vendió en 1856, siendo la mayor parte de sus compradores vecinos de Santa Cruz ${ }^{30}$.

En cuanto a la pérdida patrimonial debida al cambio de títulos de deuda pública en los bienes urbanos, el Ayuntamiento percibía 1516,5 pesetas, mientras que el 20 por ciento del devengo por los títulos le reportaría 1406,21 pesetas, lo que supone una pérdida del 7,3 por ciento. Ello se tradujo en la desaparición del patrimonio municipal que a medio plazo sufragaría, en parte, los costes de la beneficencia municipal.

29 Los valores de todas estas cargas vienen expresados en peso corriente (3,75 ptas.), real de plata (0,47 ptas.), real de vellón ( 0,25 ptas.) y tostón (1,25 ptas.), es decir, en el circulante propio del setecientos, de modo que se han unificado todas estas unidades monetarias y sus submúltiplos a la unidad peseta.

$30 \mathrm{La}$ nómina de compradores puede consultarse en OJeda Quintana (1977): op. cit., pp. 205-391. 
Ocurrió, pues, un fuerte desequilibrio en la situación financiera de las haciendas locales, agrandado además por el proceso desamortizador, al desaparecer sus rentas patrimoniales y al aumentar los costes de las obligaciones de los nuevos municipios en materia de sanidad, educación y beneficencia. Asimismo, los municipios se vieron también privados de los arbitrios que gravaban la circulación interior, como fue el caso del haber del peso, que dejó de cobrarse en el caso del tesoro local de Santa Cruz de Tenerife en $1855^{31}$.

Lo dicho revela la precaria situación financiera de las haciendas locales de mediados del siglo XIX. Para resolver su elevado desequilibrio presupuestario, el Estado debía dotarlas de una hacienda fiscal sustitutiva de la patrimonial. Así, asignó a los nuevos municipios la capacidad recaudatoria de las contribuciones estatales a cambio de concederles una participación en los impuestos estatales, cuyo objetivo era cubrir el déficit municipal.

La sostenida expansión de las economías de producción agroexportadora y de servicios durante el período 1850-1880 debió desempeñar un papel clave en la génesis de la nueva hacienda municipal de Santa Cruz, al incrementar la liquidez de su vecindario, esto es, las rentas del trabajo, de la tierra y del capital.

Cabe sugerir, pues, que hubo dineros para pagar los impuestos propios del tesoro local y del tesoro nacional, además de los recargos establecidos en provecho del primero, lo cual sugiere también otras dos cuestiones: la primera, que la historia financiera de los municipios reprodujo en esencia la estatal, y, la segunda, que el incremento de los ingresos municipales corrió paralelo al aumento de lo recaudado por las contribuciones estatales, así como de la cuota de recargo autorizada en cada momento y sobre estos impuestos por parte del Estado.

\subsection{El FUERTE CRECiMIENTO DE LOS INGRESOS}

El análisis de los presupuestos de ingresos autorizados del citado período revela su fuerte crecimiento, medido tanto en pesetas corrientes como en pesetas constantes del año 2000 ( $c f$. tabla 6$)^{32}$. Un examen más detenido muestra que los ingresos, de algo más de 50000 pesetas en 1850, subieron a 100000 pesetas después de $1852^{33}$, cerrando el período en la suma de 342805 pesetas. Considerando toda la etapa, el presupuesto de ingresos autorizados del municipio se multiplicó por casi seis puntos entre 1850 y 1880 .

${ }^{31}$ Su supresión representó la pérdida de 6300 rs vn (1575 pesetas) por dicho concepto. AMSCT, caja 1172 .

32 Hemos tomado como deflactor el propuesto por Aixala Pasto, José: La peseta y los precios. Un análisis de largo plazo (1868-1995). Zaragoza, 1999.

${ }^{33} \mathrm{La}$ caída de los ingresos en 1855 obedece a la supresión del cobro de los impuestos de consumo en este año. 


\begin{tabular}{|c|c|c|c|c|c|c|c|c|c|}
\hline \multirow{3}{*}{ Años } & \multicolumn{9}{|c|}{$\begin{array}{l}\text { TABLA 6. PRESUPUESTOS DE INGRESOS AUTORIZADOS, 1850-1880. } \\
\text { ÍNDICE BASE: } 1850-1854\end{array}$} \\
\hline & \multicolumn{2}{|c|}{ Pts año } & \multicolumn{2}{|c|}{ Pts de 2000} & \multirow{2}{*}{ AÑos } & \multicolumn{2}{|c|}{ PTS AÑo } & \multicolumn{2}{|c|}{ Pts de 2000} \\
\hline & Ptas. & ÍND. & Ptas. & ÍnD. & & Ptas. & ÍND. & Ptas. & ÍND. \\
\hline 1850 & 58538 & 68,5 & 19912165 & 69,2 & 1866 & 117689 & 137,7 & 25475188 & 88,5 \\
\hline 1851 & 63349 & 74,1 & 20703551 & 71,9 & 1867 & 127001 & 148,6 & 29814088 & 103,6 \\
\hline 1852 & 104251 & 121,9 & 34752189 & 120,8 & 1868 & 108781 & 127,2 & 28779715 & 100,0 \\
\hline 1853 & 97758 & 114,4 & 34668014 & 120,5 & 1869 & 121180 & 141,7 & 31559016 & 109,7 \\
\hline 1854 & 103552 & 121,1 & 33842642 & 117,6 & 1870 & 153527 & 179,6 & 36651462 & 127,4 \\
\hline 1855 & 34404 & 40,2 & 10425986 & 36,2 & 1871 & 238569 & 279,1 & 68344129 & 237,5 \\
\hline 1856 & 108978 & 127,5 & 29777261 & 103,5 & 1872 & 158736 & 185,7 & 45473767 & 158,0 \\
\hline 1857 & 97600 & 114,2 & 25821550 & 89,7 & 1873 & 259481 & 303,5 & 76240843 & 264,9 \\
\hline 1858 & 93371 & 109,2 & 29363513 & 102,0 & 1874 & 172912 & 202,3 & 48326921 & 167,9 \\
\hline 1859 & 81717 & 95,6 & 21968244 & 76,3 & 1875 & 294240 & 344,2 & 91126886 & 316,7 \\
\hline 1860 & 82765 & 96,8 & 22614731 & 78,6 & 1876 & 248970 & 291,2 & 71323689 & 247,9 \\
\hline 1861 & 93869 & 109,8 & 25648865 & 89,1 & 1877 & 245492 & 287,2 & 66978510 & 232,8 \\
\hline 1862 & 107747 & 126,0 & 27628936 & 96,0 & 1878 & 255511 & 298,9 & 71412189 & 248,2 \\
\hline 1863 & 146035 & 170,8 & 32892737 & 114,3 & 1879 & 255637 & 299,0 & 69746330 & 242,4 \\
\hline 1864 & 136611 & 159,8 & 29571250 & 102,8 & 1880 & 342805 & 401,0 & 100723076 & 350,0 \\
\hline 1865 & 142560 & 166,8 & 33466623 & 116,3 & & & & & \\
\hline
\end{tabular}

Fuente: AMSCT. Presupuestos en cajas. 1850: 1172-2; 1851: 1172-3; 1852: 1172-4; 1853: 1172-5; 1854: 1172-6; 1856: 1173-1; 1857: 1173-2; 1858: 1173-3; 1859: 1173-4; 1860: 1173-5; 1861: 1174-1; 1862-63: 1174-2; 1863-64: 1174-3; 1864-65: 1175-1; 1865-66: 1175-2; 1866-67: 1175-3; 1867-68: 1176-1; 1869: 1177-1; 1870-71: 1177-2; 1871-72: 1177-3; 1872-73: 1177-4; 1873-74: 1177-5; 1874-75: 1178-1; 1875-76: 1178-2; 1876-77: 1178-3; 1877-78: 1178-4; 1878-79: 1178-5; 1879-80: 1178-6.

Ahora bien, el presupuesto de ingresos autorizados era una cosa y otra bien distinta podía ser el presupuesto de ingresos realmente recaudados por los gestores de la hacienda municipal, y entre uno y otro podía existir una significativa diferencia debida, sin duda, a la falta de liquidez inmediata de las economías familiares. La comprobación de este importante extremo indica que el Tesoro local recaudó como promedio el 78,9 por ciento de los ingresos autorizados ( $c f$. tabla 7); es más, en algunos años ingresó más de lo permitido por la opción del recurso al crédito. Pero un análisis más detenido de los datos de la tabla 7 revela que la citada descortesía mostró relevancia estadística entre 1875 y 1880, cuando el presupuesto realmente recaudado se situó por término medio en torno al 64,3 por ciento del presupuesto autorizado.

El ingreso autorizado y el ingreso recaudado por habitante permiten ponderar el alcance de lo que llevamos dicho ( $c f$. tabla 8). La primera ratio creció hasta algo más que duplicarse a lo largo del período, con un incremento medio del 20,3 por ciento; la segunda, es decir, la realmente efectiva, siguió una tendencia más errática, pero su aumento de conjunto fue del 14,1 por ciento. Y como el crecimiento promedio de la población fue del 8 por ciento, cabe sostener que los vecinos de Santa Cruz soportaron una creciente fiscalidad a lo largo de estos ańos, y que una importante proporción de esta fiscalidad procedía de los impuestos estatales y de una carga impositiva indirecta que afectaba a la población asalariada. 


\begin{tabular}{ccccccccc}
\hline \multicolumn{7}{c}{ TABLA 7. INGRESOS RECAUDADOS Y SU PROPORCIÓN RESPECTO } \\
\hline \multicolumn{7}{c}{ DE LOS INGRESOS AUTORIZADOS, $1850-1880$ (PTAS. ANNO) } \\
\hline AÑos & (PTAs.) & $(\%)$ & AÑos & (PTAs.) & $(\%)$ & AÑos & (PTAs.) & $(\%)$ \\
\hline 1850 & 55253 & 94,4 & 1861 & 87227 & 92,9 & 1871 & 93074 & 39,0 \\
\hline 1851 & & & 1862 & 106153 & 98,5 & 1872 & 124073 & 78,2 \\
\hline 1852 & 85092 & 81,6 & 1863 & 118256 & 81,0 & 1873 & 182557 & 70,4 \\
\hline 1853 & 109939 & 112,5 & 1864 & 107703 & 78,8 & 1874 & 227878 & 131,8 \\
\hline 1854 & 104584 & 101,0 & 1865 & & & 1875 & 217030 & 73,8 \\
\hline 1855 & & & 1866 & 102825 & 87,4 & 1876 & 150822 & 60,6 \\
\hline 1856 & 57489 & 52,8 & 1867 & 110973 & 87,4 & 1877 & 159971 & 65,2 \\
\hline 1857 & 72437 & 74,2 & 1868 & & & 1878 & 168052 & 65,8 \\
\hline 1858 & 84444 & 90,4 & 1869 & 60137 & 49,6 & 1879 & 164297 & 64,3 \\
\hline 1859 & 75677 & 92,6 & 1870 & 72642 & 47,3 & 1880 & 225697 & 65,8 \\
\hline 1860 & 76836 & 92,8 & & & & & & \\
\hline
\end{tabular}

Fuente: $c f$. tabla 6 .

\begin{tabular}{|c|c|c|c|c|c|c|}
\hline \multicolumn{7}{|c|}{$\begin{array}{l}\text { TABLA 8. INGRESOS AUTORIZADOS E INGRESOS } \\
\text { RECAUDADOS POR HABITANTE, 1851-1880 }\end{array}$} \\
\hline & \multicolumn{2}{|c|}{ AUTORIZADO } & \multicolumn{2}{|c|}{ ReCAudAdo } & \multicolumn{2}{|c|}{ Población } \\
\hline Años & (Ptas.) & $\%$ & (PtAs.) & $\%$ & НАв. & $\%$ \\
\hline $1851-1855$ & 7,3 & & 7,1 & & 11091 & \\
\hline $1856-1860$ & 7,4 & 1,1 & 5,8 & $-18,5$ & 12596 & 13,6 \\
\hline $1861-1865$ & 9,3 & 26,0 & 7,9 & 36,1 & 13423 & 6,6 \\
\hline $1866-1870$ & 8,8 & $-5,5$ & 6,2 & $-21,5$ & 14256 & 6,2 \\
\hline $1871-1875$ & 14,8 & 68,5 & 11,1 & 78,6 & 15140 & 6,2 \\
\hline $1876-1880$ & 16,5 & 11,6 & 10,7 & $-4,0$ & 16263 & 7,4 \\
\hline Media & 10,7 & 20,3 & 8,1 & 14,1 & & 8,0 \\
\hline
\end{tabular}

Fuente: $c f$. tabla 6. La población de 1845 a 1887 se ha estimado mediante interpolación entre los datos censales.

\subsection{El elevado peso de los consumos}

La Ley municipal de 1845 estableció una clara división entre los ingresos ordinarios y extraordinarios, provenientes de los diversos capítulos de rentas percibidas únicamente por la hacienda municipal, y los ingresos derivados de los recursos establecidos para cubrir el déficit y debidos a la participación del Tesoro local en los impuestos estatales. Por consiguiente, nuestro primer análisis debe aclarar la participación de los ingresos autorizados de una y otra procedencia durante el período 1850-1880. 


\begin{tabular}{|c|c|c|c|c|c|}
\hline \multicolumn{6}{|c|}{$\begin{array}{l}\text { TABLA 9. INGRESOS ORDINARIOS Y EXTRAORDINARIOS E INGRESOS DE } \\
\text { LOS RECURSOS PARA CUBRIR EL DÉFICIT, 1850-1880 (EN PTAS. AÑO) }\end{array}$} \\
\hline \multirow[t]{2}{*}{ AÑos } & \multicolumn{2}{|c|}{$\begin{array}{l}\text { ORDINARIOS Y } \\
\text { EXTRAORDINARIOS }\end{array}$} & \multicolumn{2}{|c|}{$\begin{array}{l}\text { RECURSOS PARA } \\
\text { CUBRIR EL DÉFICIT }\end{array}$} & \multirow{2}{*}{$\begin{array}{c}\text { Total } \\
\text { INGREsos } \\
\text { (Ptas.) }\end{array}$} \\
\hline & (PtAs.) & $(\%)$ & (PtAs.) & $(\%)$ & \\
\hline 1850 & 17385,9 & 29,7 & 41152,5 & 70,3 & 58538,4 \\
\hline 1851 & 19429,2 & 30,7 & 43920,0 & 69,3 & 63349,2 \\
\hline 1852 & 40865,9 & 39,2 & 63384,6 & 60,8 & 104250,5 \\
\hline 1853 & 36204,8 & 37,0 & 61553,3 & 63,0 & 97758,1 \\
\hline 1854 & 50998,6 & 49,2 & 52553,8 & 50,8 & 103552,5 \\
\hline 1855 & 34403,8 & 100,0 & & & 34403,8 \\
\hline 1856 & 16407,3 & 15,1 & 92571,1 & 84,9 & 108978,4 \\
\hline 1857 & 27220,2 & 27,9 & 70379,6 & 72,1 & 97599,8 \\
\hline 1858 & 54275,3 & 58,1 & 39095,3 & 41,9 & 93370,5 \\
\hline 1859 & 26537,1 & 32,5 & 55180,0 & 67,5 & 81717,1 \\
\hline 1860 & 28911,9 & 34,9 & 53853,3 & 65,1 & 82765,1 \\
\hline 1861 & 40937,9 & 43,6 & 52931,5 & 56,4 & 93869,4 \\
\hline 1862 & 45344,1 & 42,1 & 62402,5 & 57,9 & 107746,6 \\
\hline 1863 & 88150,0 & 60,4 & 57885,3 & 39,6 & 146035,3 \\
\hline 1864 & 75157,0 & 55,0 & 61454,2 & 45,0 & 136611,2 \\
\hline 1865 & 80008,9 & 56,1 & 62550,6 & 43,9 & 142559,5 \\
\hline 1866 & 55112,8 & 46,8 & 62575,8 & 53,2 & 117688,5 \\
\hline 1867 & 62591,2 & 49,3 & 64409,5 & 50,7 & 127000,6 \\
\hline 1868 & 71682,2 & 65,9 & 37098,8 & 34,1 & 108781,0 \\
\hline 1869 & 49752,2 & 41,1 & 71427,3 & 58,9 & 121179,6 \\
\hline 1870 & 66944,4 & 43,6 & 86583,0 & 56,4 & 153527,4 \\
\hline 1871 & 107846,0 & 45,2 & 130723,3 & 54,8 & 238569,3 \\
\hline 1872 & 130706,7 & 82,3 & 28028,8 & 17,7 & 158735,6 \\
\hline 1873 & 152562,5 & 58,8 & 106918,5 & 41,2 & 259481,0 \\
\hline 1874 & 139884,5 & 80,9 & 33028,0 & 19,1 & 172912,5 \\
\hline 1875 & 169785,9 & 57,7 & 124454,0 & 42,3 & 294239,9 \\
\hline 1876 & 135454,3 & 54,4 & 113515,8 & 45,6 & 248970,0 \\
\hline 1877 & 143490,4 & 58,5 & 102002,0 & 41,5 & 245492,4 \\
\hline 1878 & 154429,2 & 60,4 & 101081,8 & 39,6 & 255510,9 \\
\hline 1879 & 153383,2 & 60,0 & 102253,9 & 40,0 & 255637,1 \\
\hline 1880 & 242212,4 & 70,7 & 100592,4 & 29,3 & 342804,8 \\
\hline
\end{tabular}

Fuente: $c f$. tabla 8.

Los ingresos ordinarios experimentaron un crecimiento prácticamente constante a lo largo del período, con una proporción del 70 por ciento en sus primeros años hasta alcanzar el 95 por ciento en los años finales de la década de 1870, mientras que los extraordinarios presentaron subidas puntuales debidas a ingresos de carácter eventual ( $c f$. tabla 9). En definitiva, el Consistorio desplegó un esfuerzo por mejorar las rentas ordinarias de su presupuesto, que en el desarrollo de esta estrategia obtuvo buenos resultados. 
Ahora bien, sus dos principales partidas (ingresos ordinarios y extraordinarios, y recursos para cubrir el déficit) siguieron caminos diferentes. De entrada, los recursos representaron como promedio el 50,4 por ciento del total de ingresos de los presupuestos autorizados del municipio ( $c f$. tabla 9). Tal proporción calculada en base al total de ingresos de los presupuestos recaudados representa como promedio el 53,3 por ciento de los ingresos municipales ( $c f$. tabla 10). La tesis, pues, queda perfectamente dibujada: algo más de la mitad de los ingresos de la hacienda de Santa Cruz se nutría de los recargos sobre las contribuciones estatales.

\begin{tabular}{|c|c|c|c|c|c|c|c|}
\hline \multicolumn{8}{|c|}{$\begin{array}{l}\text { TABLA 10. INGRESOS RECAUDADOS, 1850-1880. PARTICIPACIÓN } \\
\text { DE LOS RECURSOS PARA CUBRIR EL DÉFICIT (PTAS. AÑO) }\end{array}$} \\
\hline \multirow[b]{2}{*}{ AÑos } & \multirow{2}{*}{$\begin{array}{c}\text { TotAL } \\
\text { (A) }\end{array}$} & \multicolumn{2}{|c|}{ Recursos } & \multicolumn{2}{|r|}{ Total } & \multicolumn{2}{|c|}{ Recursos } \\
\hline & & (B) & $\% \mathrm{~B} / \mathrm{A}$ & Años & (A) & (B) & $\% \mathrm{~B} / \mathrm{A}$ \\
\hline 1850 & 55252,9 & 42359,7 & 76,7 & 1866 & 102824,7 & 62127,1 & 60,4 \\
\hline 1851 & & & & 1867 & 110972,8 & 63183,6 & 56,9 \\
\hline 1852 & 85092,5 & 65617,8 & 77,1 & 1868 & & & \\
\hline 1853 & 109939,1 & 84390,9 & 76,8 & 1869 & 60136,6 & 28000,0 & 46,6 \\
\hline 1854 & 104583,7 & 86711,7 & 82,9 & 1870 & 72642,2 & 18575,1 & 25,6 \\
\hline 1855 & & & & 1871 & 93073,8 & 19786,8 & 21,3 \\
\hline 1856 & 57489,5 & 16098,3 & 28,0 & 1872 & 124072,7 & 40598,5 & 32,7 \\
\hline 1857 & 72437,4 & 48004,1 & 66,3 & 1873 & 182557,4 & 78134,5 & 42,8 \\
\hline 1858 & 84444,3 & 46503,2 & 55,1 & 1874 & 227878,5 & 152926,9 & 67,1 \\
\hline 1859 & 75677,2 & 47142,2 & 62,3 & 1875 & 217029,6 & 111071,8 & 51,2 \\
\hline 1860 & 76835,5 & 43794,8 & 57,0 & 1876 & 150822,3 & 87236,5 & 57,8 \\
\hline 1861 & 87227,1 & 48797,6 & 55,9 & 1877 & 159970,6 & 100787,9 & 63,0 \\
\hline 1862 & 106152,7 & 63678,4 & 60,0 & 1878 & 168052,4 & 99383,2 & 59,1 \\
\hline 1863 & 118255,8 & 57242,8 & 48,4 & 1879 & 164297,3 & 98523,1 & 60,0 \\
\hline 1864 & 107702,8 & 62636,9 & 58,2 & 1880 & 225697,2 & 99362,2 & 44,0 \\
\hline
\end{tabular}

Fuente: $c f$. tabla 6.

Interesaría ahora concretar, en primer término, la estructura de los ingresos ordinarios y extraordinarios y, en segundo lugar, de las contribuciones estatales que engrosaban el presupuesto municipal; en ambos casos, nuestro análisis se fundamentará en los presupuestos autorizados, dadas las lagunas existentes en la serie de presupuestos recaudados.

Con respecto a la primera partida, el retroceso de los ingresos se debió al efecto de las desamortizaciones y a los incumplimientos del Estado en el pago del tres por ciento de los títulos de deuda de los bienes vendidos, de ahí que desaparecieran los ingresos del capítulo de beneficencia. Quedaron pendientes de enajenarse algunos bienes, como parte de la huerta de Ferrer, los lavaderos, las lonjas; y la actitud cicatera del Tesoro estatal queda patente en el hecho de que la hacienda municipal le siguió abonando el 20 por ciento de la renta de sus cortos propios no enajenados, como lo venía haciendo desde su constitución como Tesoro local a principios del siglo XIX. 
Los ingresos extraordinarios mantuvieron su carácter eventual -como los créditos contraídos en 1853 y 1873-1874 para construir la nueva plaza del mercado o para atender a gastos extraordinarios-, mientras que los devengados por corrección pública procedían de los ingresos realizados por el propio municipio y los integrantes en el partido judicial para sostener la cárcel del partido. En realidad, la principal partida de la estructura de los ingresos ordinarios y extraordinarios la constituían los arbitrios e impuestos establecidos en el período anterior: matadero, plaza de mercado, lavaderos públicos, etc. La evolución creciente de sus ingresos y de su participación porcentual en el conjunto de los ordinarios revela un aumento de la actividad económica asociada a estos arbitrios, dado que no hubo durante el período ningún incremento de sus cuotas impositivas.

Esto último reviste particular interés en el caso de los recargos sobre las contribuciones estatales con el fin de cubrir el déficit presupuestario anual, que recaían sobre las contribuciones territorial, industrial y comercial (en adelante con las siglas TIC) y sobre la contribución de consumos, cuyo recargo fue más generosamente admitido por aquellos organismos responsables, en último término, de solventar el déficit municipal, previa propuesta razonada del Consistorio ( $c f$. tabla 11).

Examinados en su conjunto, los recargos procedentes de las TIC aportaron el 46,6 por ciento de los recursos para cubrir el déficit, correspondiendo a los recargos sobre los consumos el 53,4 por ciento restante.

Ahora bien, en primer lugar, las TIC aportaron un ingreso a las arcas municipales en torno al 22 por ciento en los años anteriores a 1857, de modo que la principal aportación a los recursos para cubrir el déficit durante estos años procedió de los recargos sobre los consumos. La discusión política sobre su carácter regresivo, abierta por el liberalismo progresista, junto con las revueltas populares contra esta fiscalidad ${ }^{34}$, motivó un cambio de tendencia en 1858.

En efecto, ahora subió la participación de las TIC situándose en torno al 65,8 por ciento entre aquel ańo y 1867 , para iniciar luego un continuado retroceso hasta descender al 27,3 en los primeros años de la Restauración. Caía, pues, la fiscalidad sobre la renta, en consonancia con la política fiscal del nuevo gobierno, incapacitado por su propia ideología para dar una respuesta a la protesta social a la imposición indirecta, mientras que subían de forma notable los ingresos por los recargos sobre los consumos.

${ }^{34}$ Castro, Demetrio (1991): «Protesta popular y orden público: los motines de consumo», en García Delgado, J.L. (coord.): España entre dos siglos (1875-1931). Continuidad y cambio, Madrid, pp. 109-123; Pan-Montojo, Juan Luis (1994): «Lógica legal y lógica social de la contribución de consumos y los derechos de puertas». Hacienda Pública Española, Monografías I, pp. 217-229; VAllejo, Rafael (1996): «El impuesto de consumos y la resistencia antifiscal en la España de la segunda mitad del siglo XIX: un impuesto no exclusivamente urbano». Revista de Historia Económica, 14 (2), pp. 339 370; Moreno Lázaro, Javier (2003): «Fiscalidad y revueltas populares en Castilla y León durante el Bienio Progresista", Historia Agraria, (31), pp. 111-139. Moreno Lázaro, Javier (2009): Los hermanos de Rebeca. Motines y amotinados a mediados del siglo XIX en Castilla la Vieja y León. Palencia. 


\begin{tabular}{|c|c|c|c|c|c|c|c|}
\hline \multicolumn{8}{|c|}{$\begin{array}{l}\text { TABLA 11. INGRESOS POR RECARGOS EN LAS CONTRIBUCIONES ESTATALES, } \\
\text { 1850-1880 NÚMEROS ÍNDICES (BASE: 1850-1854). EN PTAS. AÑO }\end{array}$} \\
\hline \multirow{2}{*}{ AÑos } & \multicolumn{3}{|c|}{ TIC } & \multicolumn{3}{|c|}{ Consumos } & \multirow{2}{*}{$\begin{array}{r}\text { Total } \\
\text { (Ptas.) }\end{array}$} \\
\hline & (Ptas.) & ÍNDICE & $(\%)$ & (PtAs.) & ÍNDICE & $(\%)$ & \\
\hline 1850 & 10670,0 & 57,6 & 25,9 & 30482,5 & 101,3 & 74,1 & 41152,5 \\
\hline 1851 & 39920,0 & 215,6 & 90,9 & 4000,0 & 13,3 & 9,1 & 43920,0 \\
\hline 1852 & 14227,8 & 76,8 & 22,5 & 49126,9 & 163,3 & 77,5 & 63354,6 \\
\hline 1853 & 13894,3 & 75,0 & 25,5 & 40663,6 & 135,2 & 74,5 & 54557,9 \\
\hline 1854 & 13875,0 & 74,9 & 34,7 & 26160,5 & 87,0 & 65,3 & 40035,5 \\
\hline 1856 & 14222,9 & 76,8 & 21,6 & 51548,3 & 171,3 & 78,4 & 65771,1 \\
\hline 1857 & 9200,0 & 49,7 & 21,5 & 33679,6 & 111,9 & 78,5 & 42879,6 \\
\hline 1858 & 23595,3 & 127,4 & 60,4 & 15500,0 & 51,5 & 39,6 & 39095,3 \\
\hline 1859 & 33805,0 & 182,6 & 61,3 & 21375,0 & 71,0 & 38,7 & 55180,0 \\
\hline 1860 & 29458,3 & 159,1 & 54,7 & 24395,0 & 81,1 & 45,3 & 53853,3 \\
\hline 1861 & 27081,5 & 146,3 & 51,2 & 25850,0 & 85,9 & 48,8 & 52931,5 \\
\hline 1862 & 40636,0 & 219,5 & 65,1 & 21766,5 & 72,4 & 34,9 & 62402,5 \\
\hline 1863 & 41610,3 & 224,7 & 71,9 & 16275,0 & 54,1 & 28,1 & 57885,3 \\
\hline 1864 & 45179,2 & 244,0 & 73,5 & 16275,0 & 54,1 & 26,5 & 61454,2 \\
\hline 1865 & 46051,4 & 248,7 & 73,6 & 16499,3 & 54,8 & 26,4 & 62550,6 \\
\hline 1866 & 46076,5 & 248,8 & 73,6 & 16499,3 & 54,8 & 26,4 & 62575,8 \\
\hline 1867 & 46077,0 & 248,8 & 71,5 & 18332,5 & 60,9 & 28,5 & 64409,5 \\
\hline 1868 & 18766,3 & 101,3 & 50,6 & 18332,5 & 60,9 & 49,4 & 37098,8 \\
\hline 1869 & 36718,6 & 198,3 & 55,1 & 29958,7 & 99,6 & 44,9 & 66677,3 \\
\hline 1870 & 82500,0 & 445,5 & 63,5 & 47374,5 & 157,5 & 36,5 & 129874,5 \\
\hline 1871 & 40000,0 & 216,0 & 45,9 & 47148,8 & 156,7 & 54,1 & 87148,8 \\
\hline 1872 & 28028,8 & 151,4 & 100,0 & & & & 28028,8 \\
\hline 1873 & 28028,5 & 151,4 & 26,2 & 78890,0 & 262,2 & 73,8 & 106918,5 \\
\hline 1874 & 33028,0 & 178,4 & 100,0 & & & & 33028,0 \\
\hline 1875 & 41130,8 & 222,1 & 33,0 & 83323,2 & 276,9 & 67,0 & 124454,0 \\
\hline 1876 & 36220,3 & 195,6 & 31,9 & 77295,5 & 256,9 & 68,1 & 113515,8 \\
\hline 1877 & 22780,7 & 123,0 & 22,3 & 79221,3 & 263,3 & 77,7 & 102002,0 \\
\hline 1878 & 24952,5 & 134,8 & 24,7 & 76129,3 & 253,0 & 75,3 & 101081,8 \\
\hline 1879 & 26124,6 & 141,1 & 25,5 & 76129,3 & 253,0 & 74,5 & 102253,9 \\
\hline 1880 & 26272,7 & 141,9 & 26,1 & 74319,8 & 247,0 & 73,9 & 100592,4 \\
\hline
\end{tabular}

Nota: TIC = recargo sobre las contribuciones territorial, industrial y comercial.

Fuente: $c f$. tabla 10.

Ahora bien, la cuota de recargo sobre los consumos se mantuvo constante, en torno al 50 por ciento durante estos años. Por consiguiente, el incremento de los ingresos debe asociarse a un mayor nivel de consumo de las especies gravadas, aunque en los municipios más ricos no se produjeron reacciones de tipo social aso- 
ciadas a la carga impositiva indirecta ${ }^{35}$, si bien se requiere aún profundizar en esta línea de investigación ${ }^{36}$.

\section{LOS GASTOS DE LA NUEVA HACIENDA MUNICIPAL}

Hemos comprobado que la población de Santa Cruz se duplicó entre 1845 y 1877, y que los ingresos municipales se multiplicaron por seis puntos entre 1850 y 1880 , de modo que el municipio contó cada vez con mayor capacidad financiera para poder afrontar las dos principales partidas de su presupuesto de gastos: los costes administrativos y los de los diversos servicios públicos.

Ahora bien, el Estado no dejó nada al azar en su reiterado papel intervencionista de las haciendas locales. Su legislación reguladora del presupuesto municipal, cuya aplicación supervisaba anualmente el gobernador civil y la Diputación, determinaba cada capítulo del gasto y buena parte de sus correspondientes artículos. No obstante, cada municipio tuvo sus prioridades en función de las circunstancias, a las que en nuestro caso debemos agregar las que reclamaba un municipio que ostentaba el rango de capital provincial. Aludimos a aquellos bienes cuya mejora se hacía sentir de manera más acuciante en el colectivo vecinal santacrucero: la sanidad y la higiene públicas, la educación y la cultura.

Ya se ha señalado el impacto de la fiebre amarilla de 1861-1862, que puso a prueba la capacidad del Consistorio de Santa Cruz; un esfuerzo edilicio que debe celebrarse, pues tales establecimientos se quedaron sin rentas con que financiarse por la desamortización. El Consistorio debía afrontar nuevas cargas orientadas a mejorar las condiciones de salubridad de su población.

Asimismo, la educación primaria gratuita debía ser atendida con cargo al presupuesto municipal. En realidad, los vecinos más afortunados de sus diversas pedanías habían logrado paliar el problema educativo mediante las escuelas parroquiales y conventuales, pues no hubo pueblo insular de algo más de millar y medio de habitantes que no contara con un convento de frailes cuya dotación, constituida por los bienes cedidos al efecto por los vecinos más ricos del lugar, los obligaba a enseñar las primeras letras a los hijos del vecindario ${ }^{37}$. Además, el municipio debía

${ }^{35}$ Durante el Sexenio Revolucionario la Junta Revolucionaria de Santa Cruz determinó la abolición inmediata de los consumos. Véase SÁnCHEz DE EnCiso, Alberto (1977): «El Sexenio Revolucionario en Tenerife», en Historia General de las Islas Canarias. Las Palmas de Gran Canaria, pp. 59-100. Pero los testimonios avalan más un malestar popular contra las carestías, derivadas de la extracción de subsistencias. Véase Millares, Agustín (2004): «Luchas por las papas y el pan. Los disturbios populares de Las Palmas en 1851 y 1856». Anuario de Estudios Atlánticos, 50, pp. 319-354.

36 León Álvarez, Francisco Javier (2006): «Problemas en la administración del impuesto de consumos en la Matanza de Acentejo (Tenerife) entre finales del siglo xIX y comienzos del XX». Revista de Historia Canaria, 188, pp. 132-162; Millares, Agustín (2008): Motines insulares. Tres estudios. Santa Cruz de Tenerife.

37 Béthencourt, Antonio (1984-1986): «La enseñanza en Tenerife en 1790: situación y plan para financiar la dotación de escuelas públicas». Revista de Historia Canaria, pp. 33-61. BÉTHEN- 
costear el salario del maestro y el alquiler del recinto escolar en Taganana y en San Andrés, ahora pedanías a su cargo.

\subsection{La estructura general Del gasto}

Verifiquemos, pues, el grado en que el Consistorio santacrucero respondió a las demandas de bienes preferentes de sus ciudadanos durante la fase de cimentación de la hacienda municipal (1850-1880). Y lo primero sería medir la diferencia entre los gastos autorizados (A) y los gastos efectivamente pagados (B) en cada ejercicio presupuestario ( $c f$. tabla 12). Así, la proporción promedio representada entre ambos durante todo el período fue del 76,2 por ciento, si bien un examen más detenido revela una caída luego de 1869, situándose entre este año y 1880 en el 54,7 por ciento; por consiguiente, en la década de 1870, el Consistorio únicamente atendió a algo más de la mitad de los gastos del presupuesto autorizado, en consonancia con un comportamiento del mismo signo en el presupuesto recaudado. De ahí que el promedio de gasto pagado por habitante en los años 1850-1880, de 8,1 pesetas ( $c f$. tabla 8), fuera exactamente igual al promedio de ingreso recaudado por habitante, siendo más elevado en el último quinquenio.

\begin{tabular}{|c|c|c|c|c|c|c|c|c|c|}
\hline \multicolumn{10}{|c|}{$\begin{array}{l}\text { TABLA 12. PRESUPUESTO DE GASTOS AUTORIZADOS Y DE GASTOS PAGADOS } \\
\text { Y POR HABITANTE, 1850-1880 (PTAS. AÑO) }\end{array}$} \\
\hline \multirow{2}{*}{ Años } & \multirow{2}{*}{ Autor. } & \multicolumn{2}{|c|}{ PaGados } & \multirow{2}{*}{$\begin{array}{l}\text { POR } \\
\text { HAB. }\end{array}$} & \multirow{2}{*}{ AÑos } & \multirow{2}{*}{ AuTOR. } & \multicolumn{2}{|c|}{ PaGados } & \multirow{2}{*}{$\begin{array}{l}\text { POR } \\
\text { HAB. }\end{array}$} \\
\hline & & B & B/A\% & & & & B & $\mathrm{B} / \mathrm{A} \%$ & \\
\hline 1850 & 53317,9 & 60330,7 & 113,2 & 6,0 & 1866 & 120065,7 & 102029,9 & 85,0 & 7,3 \\
\hline 1851 & 63945,8 & 56566,8 & 88,5 & 5,4 & 1867 & 126948,8 & 109404,8 & 86,2 & 7,8 \\
\hline 1852 & 105498,2 & 75517,5 & 71,6 & 7,0 & 1868 & 135017,3 & 108576,0 & 80,4 & 7,6 \\
\hline 1853 & 98316,6 & 109897,6 & 111,8 & 9,9 & 1869 & 121229,6 & 63526,8 & 52,4 & 4,4 \\
\hline 1854 & 66038,2 & 104573,7 & 158,4 & 9,2 & 1870 & 154286,0 & 71414,4 & 46,3 & 4,9 \\
\hline 1855 & 66946,9 & 81377,0 & 121,6 & 6,9 & 1871 & 238815,7 & 93056,0 & 39,0 & 6,3 \\
\hline 1856 & 67052,4 & 57485,3 & 85,7 & 4,7 & 1872 & 282358,0 & 124072,7 & 43,9 & 8,3 \\
\hline 1857 & 107793,3 & 71420,2 & 66,3 & 5,7 & 1873 & 299988,3 & 181044,7 & 60,4 & 12,0 \\
\hline 1858 & 138268,2 & 82982,0 & 60,0 & 6,6 & 1874 & 409943,1 & 221708,7 & 54,1 & 14,5 \\
\hline 1859 & 95185,2 & 75415,8 & 79,2 & 5,9 & 1875 & 331599,9 & 216763,3 & 65,4 & 14,0 \\
\hline 1860 & 89585,8 & 76416,2 & 85,3 & 5,9 & 1876 & 281527,1 & 150695,8 & 53,5 & 9,6 \\
\hline 1861 & 92462,0 & 83145,2 & 89,9 & 6,4 & 1877 & 272248,2 & 159381,7 & 58,5 & 10,0 \\
\hline 1862 & 107296,2 & 95571,0 & 89,1 & 7,2 & 1878 & 276028,5 & 167989,4 & 60,9 & 10,4 \\
\hline 1863 & 145665,1 & 118031,7 & 81,0 & 8,8 & 1879 & 272571,1 & 164164,1 & 60,2 & 9,9 \\
\hline 1864 & 138332,1 & 105476,2 & 76,3 & 7,8 & 1880 & 353961,6 & 218071,1 & 61,6 & 12,9 \\
\hline 1865 & 142203,6 & 107937,6 & 75,9 & 7,9 & & & & & \\
\hline
\end{tabular}

Nota: los gastos pagados en 1855 y 1868 se han estimado a partir del promedio del quinquenio anterior.

Fuente: $c f$. tabla 6.

Court, Antonio (1987): «Una jornada escolar en Las Palmas de Gran Canaria en 1775». Boletín Millares Carlo, 9-10, 141-154. 
Para determinar la estrategia seguida por el Ayuntamiento en el empleo de los ingresos, hemos agrupado los diversos capítulos de los gastos municipales en dos partidas principales claramente definidas por su funcionalidad. De un lado, los capítulos que son propios de la administración municipal y, por lo tanto, con una asignación presupuestaria comprometida de antemano en cada ejercicio (partida $\mathrm{A}$ de la tabla 13), y, de otro, el conjunto de capítulos del gasto relacionados de forma más directa con las demandas e intereses de la ciudadanía (partida B de la tabla 13).

\begin{tabular}{|c|c|c|c|c|c|c|c|c|c|c|c|c|c|}
\hline \multirow{2}{*}{ AÑos } & \multicolumn{11}{|c|}{ Capítulos } & \multicolumn{2}{|c|}{ Partidas } \\
\hline & 1 & 2 & 3 & 4 & 5 & 6 & 7 & 8 & 9 & 10 & 11 & A & B \\
\hline 1850 & 25,5 & 1,9 & 13,8 & 8,0 & 22,9 & 2,6 & 10,0 & 2,6 & 0,5 & 11,3 & 0,9 & 40,0 & 60,0 \\
\hline 1851 & 25,1 & & 7,5 & 15,3 & 19,1 & 1,6 & 10,7 & 1,8 & 11,7 & 6,3 & 1,0 & 26,9 & 73,1 \\
\hline 1852 & 16,0 & & 5,4 & 9,0 & 12,8 & 1,0 & 10,8 & 1,4 & 12,9 & 29,7 & 0,9 & 17,4 & 82,6 \\
\hline 1853 & 22,8 & & 6,9 & 13,0 & 19,1 & 0,9 & 9,6 & 2,0 & 19,7 & 5,5 & 0,5 & 24,8 & 75,2 \\
\hline 1854 & 21,8 & & 7,8 & 14,1 & 0,8 & 0,6 & 24,9 & 2,8 & 13,2 & 11,3 & 2,6 & 24,6 & 75,4 \\
\hline 1855 & 27,0 & & 9,9 & 16,8 & 0,9 & 1,1 & 16,8 & 3,4 & 11,8 & 5,4 & 6,8 & 30,4 & 69,6 \\
\hline 1856 & 23,8 & 9,0 & 10,0 & 14,6 & 0,4 & 1,1 & 15,3 & 3,6 & 10,1 & 9,9 & 2,3 & 36,5 & 63,5 \\
\hline 1857 & 21,0 & 5,7 & 8,3 & 10,8 & & 1,4 & 9,3 & 2,6 & 17,6 & 20,2 & 3,2 & 29,3 & 70,7 \\
\hline 1858 & 18,5 & 3,7 & 10,0 & 8,8 & & 7,7 & 7,0 & 2,1 & 28,3 & 11,8 & 2,1 & 24,3 & 75,7 \\
\hline 1859 & 29,8 & 1,3 & 11,9 & 13,4 & & 7,7 & 8,9 & 3,1 & 16,2 & 1,8 & 6,0 & 34,3 & 65,7 \\
\hline 1860 & 27,1 & 5,5 & 10,7 & 13,1 & & 11,7 & 10,9 & 2,9 & 15,5 & & 2,7 & 35,5 & 64,5 \\
\hline 1861 & 22,6 & 10,9 & 17,0 & 12,4 & 0,1 & 11,3 & 10,2 & 2,8 & 10,4 & & 2,3 & 36,3 & 63,7 \\
\hline 1862 & 19,4 & 9,5 & 16,3 & 10,5 & 2,8 & 13,0 & 9,0 & 2,4 & 14,0 & 1,0 & 2,2 & 31,3 & 68,7 \\
\hline 1863 & 14,8 & 7,8 & 14,6 & 10,1 & 0,1 & 15,8 & 7,5 & 1,8 & 16,1 & 9,8 & 1,7 & 24,3 & 75,7 \\
\hline 1864 & 18,6 & 9,3 & 19,2 & 11,1 & 0,2 & 12,2 & 10,3 & 2,3 & 10,7 & 0,6 & 5,6 & 30,2 & 69,8 \\
\hline 1865 & 18,2 & 8,8 & 19,0 & 11,2 & 0,2 & 13,8 & 11,9 & 2,1 & 12,3 & 1,3 & 1,2 & 29,1 & 70,9 \\
\hline 1866 & 21,5 & 9,9 & 21,5 & 11,8 & 0,2 & 13,3 & 8,3 & 2,3 & 9,5 & & 1,8 & 33,7 & 66,3 \\
\hline 1867 & 19,1 & 10,4 & 22,4 & 11,4 & 0,2 & 12,4 & 8,1 & 2,2 & 12,5 & 0,5 & 0,8 & 31,7 & 68,3 \\
\hline 1868 & 20,3 & 9,5 & 22,5 & 9,8 & 0,2 & 12,2 & 11,6 & 2,1 & 9,9 & 0,8 & 1,2 & 31,8 & 68,2 \\
\hline 1869 & 19,1 & 11,0 & 21,9 & 11,7 & 0,2 & 14,0 & 11,3 & 1,8 & 7,7 & 0,1 & 1,2 & 31,9 & 68,1 \\
\hline 1870 & 18,6 & 8,8 & 19,0 & 11,4 & 0,1 & 9,1 & 12,5 & 1,7 & 17,6 & 0,1 & 1,1 & 29,0 & 71,0 \\
\hline 1871 & 17,2 & 12,2 & 15,5 & 9,9 & 0,1 & 11,0 & 10,4 & 1,5 & 19,7 & 0,1 & 2,4 & 30,9 & 69,1 \\
\hline 1872 & 16,1 & 12,2 & 14,0 & 8,6 & 0,1 & 6,8 & 3,8 & 1,3 & 32,3 & 2,5 & 2,3 & 29,6 & 70,4 \\
\hline 1873 & 15,5 & 12,8 & 12,6 & 8,6 & 0,1 & 6,2 & 6,9 & 1,4 & 33,0 & & 2,7 & 29,7 & 70,3 \\
\hline 1874 & 9,8 & 7,9 & 7,2 & 4,6 & 0,4 & 4,0 & 4,1 & 0,7 & 57,2 & 2,7 & 1,5 & 18,4 & 81,6 \\
\hline 1875 & 16,2 & 7,5 & 8,5 & 6,2 & 0,5 & 8,4 & 5,5 & 0,8 & 45,3 & & 1,1 & 24,5 & 75,5 \\
\hline 1876 & 20,1 & 10,2 & 11,3 & 8,1 & 0,7 & 12,9 & 7,2 & 0,9 & 23,1 & 4,1 & 1,4 & 31,2 & 68,8 \\
\hline 1877 & 16,6 & 10,5 & 13,6 & 8,5 & 0,5 & 8,9 & 6,9 & 1,0 & 29,7 & 2,3 & 1,5 & 28,0 & 72,0 \\
\hline 1878 & 16,5 & 10,5 & 13,1 & 14,0 & 0,5 & 13,8 & 6,8 & 1,3 & 22,0 & & 1,5 & 28,2 & 71,8 \\
\hline 1879 & 16,1 & 9,9 & 12,6 & 13,6 & 0,5 & 12,1 & 7,1 & 1,2 & 25,5 & & 1,4 & 27,1 & 72,9 \\
\hline 1880 & 11,0 & 7,2 & 8,0 & 10,1 & 0,7 & 17,8 & 4,9 & 0,8 & 37,7 & 1,0 & 1,0 & 19,0 & 81,0 \\
\hline
\end{tabular}

1. Ayuntamiento; 2. Policía de seguridad; 3. Policía urbana; 4. Instrucción pública; 5. Beneficencia. 6. Obras públicas: 7. Corrección pública; 8 . Montes; 9. Cargas; 10. Obras nuevas; 11. Imprevistos.

Fuente: cf. tabla 12 
La primera partida (A) incluiría los siguientes capítulos: los gastos propios de la administración municipal (salarios, material de oficina y gastos de representación), hasta aquellos otros gastos debidos a la gestión de los servicios estatales que corrían a cargo del municipio (confección de estadísticas, elecciones, reclutamiento); y los de policía de seguridad (guardia municipal, cuerpo de serenos, de bomberos; vestuarios de estos empleados y materiales y seguro de incendios).

En el capítulo séptimo, de corrección pública (sueldos de alcaide y alguaciles, materiales y manutención de presos pobres), aunque cabe señalar que este contaba con la aportación dineraria de los municipios que conformaban el partido judicial; y el octavo, de montes, que se refería a los sueldos de los guardas forestales.

La segunda partida englobaría el resto de los capítulos, es decir, los relacionados con los diversos servicios municipales que demandaba la ciudadanía: Policía urbana (3); Instrucción pública (4); Beneficencia (5); Obras públicas (6); Cargas financieras (9); Obras nuevas (10); Imprevistos (11).

La conclusión que se desprende de esta primera aproximación a los gastos del tesoro local de Santa Cruz de Tenerife del período 1850-1880 contradice la tesis que otorga a los gastos administrativos un porcentaje superior al 50 por ciento del total de gastos ${ }^{38}$; una regla que hemos confirmado en los primeros presupuestos municipales de dicho municipio, y que ahora no se verifica, pues esta prioritaria partida del gasto municipal, denominada partida A en la tabla 13, absorbió como promedio durante el período 1850-1880 un 29 por ciento del presupuesto total de gastos autorizados.

Por consiguiente, el Consistorio dispuso en estos años de un amplio margen de maniobra para poder atender la demanda de bienes preferentes; una opción estratégica que pudo desarrollarse gracias a la riqueza generada por la coyuntura económica que vivió el municipio durante este período.

\subsection{LAS INVERSIONES EN BIENES PREFERENTES}

Nuestro análisis comienza por el capítulo tercero, de policía urbana. Los gastos autorizados en este capítulo representaron como promedio el 13,3 por ciento del total de gastos autorizados durante el período 1850-1880, si bien con una mayor participación porcentual en los años 1861-1869, del orden del 22 por ciento ( $c f$. tablas 13 y 14).

El examen del gasto autorizado en cada uno de sus artículos revela la elevada importancia del alumbrado público, que absorbió el 55,7 por ciento de los totales autorizados del capítulo, con una inversión media anual de 9575 pesetas ( $c f$. tabla 14). Además, interesa observar que la preocupación por el alumbrado público comenzó en los primeros años de la hacienda municipal. La escasez de sus fondos

38 Comín, Francisco y García, Carmen (1995): «Reforma liberal, centralismo y Haciendas municipales en el siglo XIX». Hacienda Pública Española, 133, pp. 81-106. 
trasladó entonces el problema al vecindario, de modo que su desarrollo inicial fue posible gracias a la iniciativa de los vecinos principales, que costearon los faroles y el combustible necesario - primero, aceite de oliva, y belmontina a partir de $1863^{39}{ }^{-}$. Por consiguiente, el Consistorio, dotado por fin con fondos, contó con una red de alumbrado público antes de su intervención en esta materia, que se concretó ahora en ampliar dicha red y resolver los problemas inherentes a su servicio ${ }^{40}$.

\begin{tabular}{lrrr}
\hline \multicolumn{4}{c}{$\begin{array}{c}\text { TABLA 14. GASTOS AUTORIZADOS EN POLICÍA } \\
\text { URBANA, }\end{array}$} \\
\hline \multicolumn{1}{c}{ Artículos } & $\begin{array}{c}\text { Total } \\
\text { INVERTIDO }\end{array}$ & $\begin{array}{c}\text { MEDiA } \\
\text { ANUAL }\end{array}$ & $(\%)$ \\
\hline Generales & 28042,9 & 905,0 & 5,3 \\
\hline Alumbrado & 296823,0 & 9575,0 & 55,7 \\
\hline Limpieza & 31151,4 & 1005,0 & 5,8 \\
\hline Arbolado & 46487,1 & 1500,0 & 8,7 \\
\hline Mercado & 19731,0 & 636,0 & 3,7 \\
\hline Matadero & 87198,3 & 2813,0 & 16,4 \\
\hline Cementerio & 23290,0 & 751,0 & 4,4 \\
\hline Totales & 532723,6 & 17184,6 & 100,0 \\
\hline Fuente: $c$ f tabla 6. & & &
\end{tabular}

El gasto autorizado en los capítulos de obras públicas y de obras de nueva construcción representó el 13,1 por ciento del total de gastos autorizados entre 1850 y 1880 ( $c f$. tabla 13). El examen del dinero autorizado a ser invertido en sus diversos artículos reporta algunas sorpresas ( $c f$. tabla 15).

\begin{tabular}{|c|c|c|c|}
\hline \multicolumn{4}{|c|}{$\begin{array}{l}\text { TABLA 15. GASTOS AUTORIZADOS EN OBRAS PÚBLICAS, } \\
\text { 1850-1880 (EN PTAS. AÑO) }\end{array}$} \\
\hline \multirow{2}{*}{ Artículos } & TOTAL & Media & (\%) \\
\hline & INVERTIDO & ANUAL & (\%) \\
\hline Mantenimiento de edificios públicos & 31168,1 & 1005,4 & 5,9 \\
\hline Caminos vecinales y puentes & 19010,0 & 613,2 & 3,6 \\
\hline Fuentes y cañerías & 67696,9 & 2183,8 & 12,8 \\
\hline Alcantarillado & 4378,7 & 141,3 & 0,8 \\
\hline Aceras, empedrado y adoquinado & 137921,9 & 4449,1 & 26,1 \\
\hline Puestos públicos & 3889,6 & 125,5 & 0,7 \\
\hline Cementerio & 13583,2 & 438,2 & 2,6 \\
\hline Alamedas y paseos & 80826,4 & 2607,3 & 15,3 \\
\hline Teatro & 27426,3 & 884,7 & 5,2 \\
\hline Obras varias & 143363,4 & 4624,6 & 27,1 \\
\hline Totales & 529264,4 & 17073,1 & 100,0 \\
\hline
\end{tabular}

Fuente: $c f$. tabla 14 .

39 Pérez Hernández (2016): op. cit.

40 Cioranescu (1998): op. cit., t. iII, pp. 508-511. 
No parece que preocupara al Consistorio el alcantarillado, a tenor del bajo porcentaje invertido $(0,8 \%)$, lo que sugiere que no fue necesario acometer importantes obras para drenar las aguas contaminadas de un vecindario que casi dobló su número en este período, a pesar de la amenaza latente de un posible contagio de cólera morbo.

El abastecimiento de agua potable dejó de ser un problema en esta etapa ${ }^{41}$, de modo que la labor inversora al respecto se limitó esencialmente a la apertura de nuevas fuentes públicas en los barrios que demandaban este servicio, y a realizar las preceptivas obras de mantenimiento de la red, destinándose a todo ello el 12,8 por ciento del total invertido en estos dos capítulos. Partidas de menor cuantía se emplearon en la conservación de los edificios públicos, en el arreglo de caminos y puentes y en la construcción de un nuevo cementerio, acelerado, además, por la epidemia de fiebre amarilla. Finalmente, destacan los importes destinados a mejorar las infraestructuras que requiere la economía de servicios de la urbe y su embellecimiento. Así, el gasto en aceras y calles absorbió el 26,1 por ciento del total de gastos autorizados, y los paseos y alamedas el $15,3 \%$ por ciento. Finalmente, destaca la construcción del Teatro municipal ${ }^{42}$, en la línea de dotar a la urbe del recinto cultural demandado por sus elites.

El gasto autorizado en el capítulo de instrucción pública representó del 11 por ciento del total de gastos autorizados entre 1850 y 1880 ( $c f$. tablas 13 y 16). En términos de gasto por habitante, subió de 0,80 pesetas en 1857 a 1,2 pesetas en 1880 , cuando en el conjunto regional esta ratio subió de 0,41 pesetas a 0,88 pese$\operatorname{tas}^{43}$. Ahora bien, a este apartado debemos agregarle la participación del Consistorio en la financiación de la Academia de Bellas Artes ${ }^{44}$, que por la vía del capítulo de cargas recibió una media de 3240 pesetas anuales en los ejercicios de 1851 a 1876-77, y la Escuela de Náutica ${ }^{45}$, que por igual vía ingresó 936 pesetas en los ejercicios de 1851 a 1861 .

41 Cola: op. cit., 2009, pp. 101-109.

42 Expediente devuelto por Comisión con planos, presupuesto, etc., formado por arquitecto titular por Academia de S. Ferodo d. Manuel Oraa. Se aprueba y se «anuncie subasta de obra, cuyo remate se verifique el dia 24 de febrero por el Sr Alcalde Presidente, con asistencia del Procurador Síndico", en AMSCT, libro de Actas, 1848, fol. 16.

43 Macías, Antonio Manuel (1998): Voz «Educación», en Macías, A.M. (ed.): Gran Enciclopedia Canaria. Santa Cruz de Tenerife, t. vi, pp. 1351-1353.

${ }_{44}$ Fue establecida en Santa Cruz de Tenerife por Real Decreto de 31 de octubre de 1849. Macías, Antonio Manuel: Voz «Academia de Bellas Artes de Canarias», en Macías, A.M. (ed.) (1994): Gran Enciclopedia Canaria. Santa Cruz de Tenerife, t. I, pp. 42-43.

${ }^{45}$ La Junta de Comercio, dependiente de la Diputación Provincial y con sede en Santa Cruz de Tenerife, asumió la creación de dicha Escuela en 1835. La Real Orden de 24 de marzo de 1850 incorporó sus estudios al Instituto de Canarias, pero las clases siguieron impartiéndose en Santa Cruz; en 1869 pasó a ser financiada por la Diputación Provincial. Véase Macías, Antonio Manuel: Voz «Escuela de Náutica», en Macías, A.M. (ed.) (1998): Gran Enciclopedia Canaria. Santa Cruz de Tenerife, t. vi, p. 1412. 


\begin{tabular}{|c|c|c|c|}
\hline \multicolumn{4}{|c|}{$\begin{array}{l}\text { TABLA 16. GASTOS AUTORIZADOS EN INSTRUCCIÓN PÚBLICA, } \\
\text { 1850-1880 (EN PTAS. AÑO) }\end{array}$} \\
\hline Artículos & $\begin{array}{c}\text { TOTAL } \\
\text { INVERTIDO }\end{array}$ & $\begin{array}{l}\text { Media } \\
\text { ANUAL }\end{array}$ & $(\%)$ \\
\hline Personal de instrucción primaria & 254240,4 & 8201,3 & 61,2 \\
\hline Material y reparaciones & 44479,8 & 1434,8 & 10,7 \\
\hline Gastos de la Junta Local & 625,0 & 20,2 & 0,2 \\
\hline Escuela de párvulos & 4625,0 & 149,2 & 1,1 \\
\hline Alquiler de edificios para escuelas & 81999,0 & 2645,1 & 19,7 \\
\hline Premios para mejorar la enseńanza & 29727,5 & 959,0 & 7,2 \\
\hline Totales & 415696,6 & 13409,6 & 100,0 \\
\hline
\end{tabular}

Fuente: $c f$. tabla 6.

\begin{tabular}{lrrr}
\hline \multicolumn{4}{c}{ TABLA 17. GASTO AUTORIZADO EN EL CAPÍTULO DE CARGAS, } \\
\multicolumn{1}{c}{ Principales ARTículos } & $\begin{array}{c}\text { TOTAL } \\
\text { INVERTIDO }\end{array}$ & $\begin{array}{c}\text { MEDIA } \\
\text { ANUAL }\end{array}$ & \multicolumn{1}{c}{$(\%)$} \\
\hline Funciones de iglesia & 37492,6 & 1209,4 & 4,3 \\
\hline Jubilaciones y viudedades & 22268,0 & 718,3 & 2,5 \\
\hline Deudas y réditos de censos & 47755,2 & 1540,5 & 5,5 \\
\hline Intereses de los créditos & 73870,2 & 2382,9 & 8,4 \\
\hline Pago de los créditos & 126827,4 & 4091,2 & 14,5 \\
\hline Indemnización de terrenos expropiados & 91347,5 & 2946,7 & 10,4 \\
\hline Academia de Bellas Artes & 84238,0 & 2717,4 & 9,6 \\
\hline Escuela de Náutica & 10290,6 & 332,0 & 1,2 \\
\hline Subvenciones & 44027,5 & 1420,2 & 5,0 \\
\hline Impuestos de bienes no desamortizados & 43573,6 & 1405,6 & 5,0 \\
\hline Comisión de evaluaciones & 27235,0 & 878,6 & 3,1 \\
\hline Contingente para gastos provinciales & 265378,5 & 8560,6 & 30,4 \\
\hline Totales & 874304,2 & 28203,4 & 100,0 \\
\hline
\end{tabular}

Fuente: $c f$. tabla 6.

Por último, el capítulo de cargas, que se refería a los compromisos asumidos por la tesorería municipal, absorbió el 19,5 por ciento de los gastos totales autorizados, incrementándose su peso especialmente en los ańos de 1872 a 1880, cuando aquella proporción subió al 34 por ciento ( $c f$. tablas 13 y 17).

Esta tendencia sugiere que el Consistorio aumentó sus cargas confiando en el sostenido crecimiento de sus ingresos; el problema se presentaba cuando los compromisos adquiridos se convertían en una pesada losa al contraerse los ingresos, y esto fue lo que ocurrió a medida que avanzaba la década de 1870 y como consecuencia de la crisis de la grana. Asistimos así a un ciclo cuya primera fase es el aumento de los ingresos, luego el endeudamiento y, finalmente, la crisis de la hacienda al coincidir el elevado endeudamiento con la contracción de los ingresos.

El examen de los principales artículos arroja una mejor comprensión de lo que llevamos dicho. Destacan entre los artículos referidos a la propia hacienda municipal sus deudas, constituidas por los réditos de censos (el abonado a los here- 
deros del Monte Aguirre) y los pagos e intereses de los créditos contraídos en 1852 para la construcción de la nueva plaza del mercado y, posteriormente, para la obra del Teatro, representando ambas partidas el 22,9 por ciento del gasto; le seguían las subvenciones a la Academia de Bellas Artes, a la Escuela de Náuticas y a otras entidades culturales $(15,8 \%)$, mientras que las indemnizaciones por terrenos expropiados para la apertura de calles $(10,4 \%)$ demuestra la acción edilicia en el crecimiento urbano. Las otras cargas responden en realidad a compromisos con la hacienda nacional por realizar obligaciones por encargo de esta última (Comisión de evaluaciones) y por el 20 por ciento que aún abonaban los bienes de propios no desamortizados (la huerta de Ferrer). Finalmente, el contingente para gastos provinciales, es decir, para la Diputación Provincial, constituía la principal carga del tesoro local (30,4\%).

\section{CONCLUSIONES}

La historia del municipio de Santa Cruz de Tenerife, de continuados fracasos y parciales éxitos, cambió a partir de 1850, cuando el ingreso efectivamente recaudado por habitante subió de 7,1 a 10 pesetas en la década de 1870 . El tesoro local contó entonces con recursos para comenzar a atender con mejor fortuna las demandas de bienes preferentes del vecindario, pudiendo incluso recurrir al crédito para resolver sus necesidades inmediatas de liquidez. Por consiguiente, fue durante estos treinta años de la centuria decimonónica cuando la capital de la provincia de Canarias cimentó las bases de una urbe de corte moderno, participando en este proceso los dineros de su municipio.

Los ingresos aumentaron gracias a la configuración de esta nueva hacienda local. Los bienes de la vieja hacienda, de carácter patrimonial y de escasa entidad, desaparecieron con el proceso desamortizador, cuya ideología liberal afectó incluso al patrimonio concejil con mayor potencial de riqueza, el subsuelo hídrico, al tiempo que las nuevas medidas legales en materia del mercado interior suprimieron las pocas rentas procedentes de antiguos arbitrios sobre la circulación de mercancías.

La reforma de la hacienda estatal de Mon-Santillán (1845) permitió la formación de la nueva hacienda municipal, de naturaleza estrictamente fiscal. A partir de ahora debía financiarse únicamente con arbitrios e impuestos sobre la actividad productiva y comercial, pudiendo cubrir el déficit mediante recargos sobre las contribuciones estatales, especialmente sobre los principales bienes de consumo. Y como los impuestos sobre estos bienes afectaban en mayor medida a la población que se sustentaba con el pan de la plaza, los ingresos de la nueva hacienda municipal dependían de la existencia de un aparato productivo y mercantil capaz de dotar a este amplio colectivo de consumidores de unas rentas del trabajo que pudieran soportar la creciente, regresiva e injusta imposición fiscal indirecta. Más aún si consideramos que la cuota correspondiente al tesoro estatal sufrió un recargo del 50 por ciento por término medio y con destino al tesoro local.

En definitiva, el crecimiento de los ingresos demuestra que Santa Cruz contó con este necesario e imprescindible concurso de la economía. El decreto de Puertos Francos de 1852 eliminó el proteccionismo, de modo que el Archipiélago recuperó 
su secular vocación librecambista. Asimismo, la economía agroexportadora conoció entre 1850 y 1880 una nueva expansión gracias al nopal y su cochinilla, que incluso tuvo su espacio en el municipio, al contar por primera vez en su historia con una oferta exportadora. Por su parte, la economía de servicios marítimos de los puertos insulares amplió su tradicional vinculación al tráfico internacional a medida que se incrementaba el flujo de hombres y mercancías en el escenario mercantil atlántico, así como el comercio, el puerto y sus industrias asociadas.

Recibido: 01-03-2019. Aceptado: 11-04-2019 
